\title{
Evaluation of the particle sizes of four clay minerals
}

${ }^{1}$ Department of Civil \& Environmental Engineering, Louisiana State University, Baton Rouge, LA 70803, USA

${ }^{2}$ School of Civil Engineering and Architecture, Xi'an University of Technology, Xi'an, Shaanxi, 710048, China

${ }^{3}$ State Key Laboratory of Hydroscience and Engineering, Tsinghua University, Beijing, 100084, China

${ }^{4}$ Naval Research Laboratory, Stennis Space Center, MS 39529, USA

${ }^{5}$ Department of Civil \& Environmental Engineering, University of Massachusetts Amherst, Amherst, MA 01003, USA

\begin{abstract}
The particle size distributions (PSD) of four clay minerals from the US Clay Minerals Society, kaolinite, illite, $\mathrm{Ca}^{2+}$-montmorillonite, and $\mathrm{Na}^{+}$-montmorillonite, were analyzed using different dispersion techniques to evaluate their PSD variability and intrinsic particle sizes. Both dry dispersion in pressurized air and wet dispersion in water and ethyl alcohol with and without an interlayer expanding agent, glycerol, were employed, along with mechanical ultrasound disaggregation and chemical dispersion. Results show that all four clay minerals exhibit multimodal PSD consisting of superimposed subordinate lognormal distributions from submicron and 1-2 $\mu \mathrm{m}$ primary particles, 10-20 $\mu \mathrm{m}$ flocculi (and trace impurities). Microflocs of 50-500 $\mu \mathrm{m}$ occur only in the dry dispersion mode. Owing to the presence of relatively strong flocculi that are not prone to breakdown to smaller primary particles, the intrinsic PSD of these clay minerals cannot be readily obtained by the adopted dispersion methods. The two swelling clay minerals, $\mathrm{Na}^{+}$-montmorillonite and $\mathrm{Ca}^{2+}$-montmorillonite, are more sensitive than the nonswelling ones, kaolinite and illite, to different dispersion solvents. The variability of these clay minerals' PSD is further discussed in terms of the complex interactions among clay mineral particles, polar or less polar solvent, and dispersant, such as swelling, cation exchange, exfoliation, and electrical double layer repulsion. A significant practical implication is that most existing dispersion methods for PSD analysis tend to overestimate the silt-sized fraction but
\end{abstract}

\footnotetext{
* Corresponding author; Phone: +1 (413) 545-3970; Email: zhangg@umass.edu or gzhang@alum.mit.edu.
} 
33 underestimate the clay-sized fraction, which may yield misleading classification for clay 34 mineral-rich soils. For expansive clay minerals, appropriate dispersants should be selected to 35 avoid cation exchange between the sample and dispersants, which can change their intrinsic PSD.

\section{Keywords:}

38 Clay mineral; Dispersion; Exfoliation; Floc; Flocculus; Particle size distribution 39 


\section{Introduction}

Clay minerals are the major solid constituents of cohesive soils, most dispersed sediments,

42 and some fine-grained rocks. As a naturally occurring geomaterial, clay minerals are also one of

43 the most important mineral resources used in many industrial and domestic applications. The

44 particle size or size distribution of clay minerals is a key parameter for mineral identification (i.e.,

45 usually requiring size separation) and soil's engineering classification, as well as understanding a

46 soil's mechanical, physical, and chemical properties that are in turn of critical importance for

47 many environmental processes and industrial applications, such as water quality monitoring,

48 environmental abatement, sediment transport, oil well drilling, clay-polymer nanocomposites,

49 and nanoclay catalysts (Walling \& Moorehead, 1989; Harvey \& Murray, 1997; Hill, 1998; Zbik

50 \& Smart, 1998; Murray, 1999; Pavlidou \& Papaspyrides, 2008; Anderson et al., 2010; Kiliaris \&

51 Papaspyrides, 2010). For instance, it is a recommended practice that separation and extraction of

52 clay fractions (i.e., $<2 \mu \mathrm{m}$ particles) is performed for qualitative and quantitative analysis, at least

53 for clay minerals (Moore \& Reynolds, 1997). In addition, particle size affects a soil’s hydraulic

54 conductivity and moisture retention capability (Daoud \& Robert, 1992) and dye and clay mineral

55 interactions (Neumann et al., 2002).

However, owing to their micrometer to sub-micrometer sizes, determination and

57 evaluation of clay minerals’ particle size distributions (PSD) are not routinely performed in most engineering or industrial practices, usually because of constraints of time or device availability.

For example, according to the ASTM Standards (ASTM, 2007), PSD are very important

60 parameters for soil classification, yet no further effort is required to characterize PSD for the $<2$

$61 \mu \mathrm{m}$ fraction or to check whether the $>2 \mu \mathrm{m}$ fraction contains non-clay minerals. As a result, all

62 particles in this fraction are collectively treated as clays without further differentiating their sizes

63 (e.g., submicrometer vs. micrometer). On the other hand, some well-crystallized clay minerals 
64 (e.g., kaolinite) may have relatively large, $>2 \mu \mathrm{m}$ particles. Although these particles are truly 65 clay minerals having chemically active surfaces, they may be counted toward the silt-sized 66 fraction, which may yield misleading soil classification and lead to inappropriate perception on 67 soils’ physico-chemical properties. The majority of existing techniques for PSD measurements require preparing an ideally 69 or appropriately dispersed clay mineral dispersion, mostly in water. A few issues arise from this 70 sample preparation process. The first one is interactions between clay mineral and water, 71 including the formation of electrical double layer on charged clay mineral surfaces, adsorbed 72 cation hydration, and intercalation of water into expandable clay minerals. Of these interactions, 73 water intercalation in swelling clay minerals can cause an initial increase in particle thickness, 74 which then may result in an increase or decrease in size, depending on the types of interlayer 75 cations or degree of swelling and other environmental conditions, as discussed later; The second 76 one is stability of the dispersion. A non-stable clay mineral dispersion can lead to particle 77 aggregation, resulting in coarser PSD; The third one is the use of chemical dispersants to obtain 78 stable clay mineral dispersions (i.e., no flocculation or aggregation). Owing to clay minerals' 79 cation or anion exchange capability, the cations or anions from dissolved dispersants may change 80 clay minerals' properties and hence alter their PSD. For example, a $\mathrm{Ca}^{2+}$-smectite may be 81 partially or completely converted via cation exchange to a $\mathrm{Na}^{+}$-smectite if a $\mathrm{Na}^{+}$-based dispersant 82 is used. After the conversion, because $\mathrm{Na}^{+}$has a stronger hydration tendency than $\mathrm{Ca}^{2+}$, the $\mathrm{Na}^{+}-$ 83 smectite can swell to a higher degree such that its interlayer spacing can theoretically increase to 84 infinity, leading to the formation of exfoliated individual 2:1 layers as separate particles. In 85 contrast, $\mathrm{Ca}^{2+}$-smectite or smectites with other divalent interlayer cations (e.g., $\mathrm{Mg}^{2+}$ ) have 86 limited swelling due to both the van der Waals and electrostatic attractions between interlayer 
87 cations and negatively charged 2:1 layers (Helmy, 1998; Segad et al., 2010). Therefore, swelling

may result in either an increase in particle size via water intercalation or decrease by exfoliation.

For clay minerals with variable PSD, another concern arises with the definition and determination of truly representative primary particles. According to the literature, primary particles usually refer to the physically solid, homogeneous, individual particles without aggregation (Zhang et al., 2005). For swelling clay minerals, primary particles are the physically coherent stacks of parallel, equally spaced aluminosilicate layers (Güven, 1992). Therefore, primary particles are intrinsic or inherent to the material, and their sizes should not be affected by different sample preparation techniques. The PSD obtained from a clay mineral dispersion that consists of only primary particles are the intrinsic PSD. That is, the intrinsic PSD reflects the particle sizes of primary particles only, but no aggregates or flocs.

It is worth noting further the importance of appropriate dispersion of dispersed clay mineral particles for PSD analysis. Due to crystal imperfections and isomorphous substitutions, most clay mineral particles possess net negative charges on face surfaces, which are balanced by adsorbed and/or interlayer cations (e.g., $\mathrm{Na}^{+}, \mathrm{K}^{+}, \mathrm{Ca}^{2+}$ ). The broken bonds on edge surfaces result in $\mathrm{pH}$ dependent charges (e.g., positive if $\mathrm{pH}$ is below the isoelectric point). As such, electrostatic forces together with other interactions, such as van der Waals attraction and double layer repulsion, between dispersed clay mineral particles usually lead to aggregation. Therefore, a clay mineral dispersion is a very complex system that contains both individual clay mineral particles and most likely clay mineral aggregates. Together with other unique features of clay mineral particles, such as irregular shapes, flexible layers, and heterogeneous layer charges, clay minerals usually exhibit a wide range of particle sizes even in pure water under stable equilibrium condition (Murray, 2000; Wu, 2001; Lagaly \& Ziesmer, 2003). 
Both mechanical and chemical methods can be used to facilitate dispersion or

111

112

113

114

115

116

117

118

119

120

121

122

123

124

125

126

127

128

129

130

131

132

disaggregation of clay minerals (Zhang et al., 2005). The former usually involves the application of mechanical energy to breakdown and separate aggregated particles, such as ultrasound disruption, flow-induced shearing in a high-speed stirrer, while the latter refers to the use of dispersants to remove or eliminate the physical cementation or chemical bonds holding particles together (Zhang et al., 2004, 2005). Therefore, accurate measurement of intrinsic PSD largely depends on the effectiveness of the employed dispersion methods to separate clay mineral aggregates or flocs and keep them stable at their primary particles in a dispersion (Crowley \& Welch, 1954). This may also require a continuous dispersion process to maintain the clay mineral dispersion at a completely dispersed, equilibrated state even during measurement. With the development of some new instruments (e.g., laser diffraction-based particle size analyzers), the size of clay mineral particles and their PSD can be quickly measured (de Boer et al., 1987) when a clay mineral dispersion is continuously circulated. Additionally, different dispersion methods, either chemical or mechanical or both, in different solvents (e.g., air, water, or a less polar liquid) can be employed for PSD measurements.

This paper presents an experimental study to evaluate the PSD of four source clay minerals, kaolinite, illite, $\mathrm{Na}^{+}$-montmorillonite $\left(\mathrm{Na}^{+}-\mathrm{Mt}\right)$, and $\mathrm{Ca}^{2+}$-montmorillonite $\left(\mathrm{Ca}^{2+}-\mathrm{Mt}\right)$,, which are abundant in natural soils and are representative of four major species of clay minerals with distinctly different behavior. Kaolinite and illite are non-swelling 1:1 and 2:1 minerals, respectively, while the two montmorillonites are swelling 2:1 minerals but with different interlayer cations as well as layer charges. The objectives of this paper are three-fold: (1) to investigate the effect of different dispersion methods on the PSD of different clay minerals, (2) to evaluate the degree of PSD variability of four source clay minerals, and (3) to obtain reference 
133 data on the PSD of these representative clay minerals. The findings are expectedly of interest to

134 primarily soil engineers and secondarily researchers who study or use clay minerals for different 135 industrial applications or environmental processes.

137 2. Experimental

\section{$138 \quad 2.1 \quad$ Materials}

Four relatively pure clay minerals, kaolinite (KGa-1b), illite (IMt-1), $\mathrm{Ca}^{2+}-\mathrm{Mt}$ (STx-1b),

140 and $\mathrm{Na}^{+}-\mathrm{Mt}$ (SWy-2), which have been well analyzed and widely used by many studies as

141 reference clay minerals, were purchased from the US Clay Minerals Society Source Clay

142 Repository (Hower \& Mowatt, 1966; Pruett \& Webb, 1993; Chipera \& Bish, 2001; Costanzo,

143 2001). Their geographic origins and basic properties are summarized in Table 1. Kaolinite and

144 two montmorillonites were supplied as dry powder, which had been pre-processed by wet-

145 sieving through a \#325 mesh to remove the $>44 \mu \mathrm{m}$ fractions before shipping to users (Pruett \&

146 Webb, 1993). These three "as-received" dry powdery clay minerals were directly used without

147 further treatment. The "as-received" illite sample consisted of small rock chips. To obtain

148 powdery illite, the sample was first hand ground by a mortar and pestle and then wet ground with

149 ethyl alcohol using a McCrone micronizing mill (McCrone Accessories \& Components,

150 Westmont, IL, USA) for 3 mins, which typically results in a fine powder with $\leq 38 \mu$ m particles

151 for most silicate minerals. To identify clay minerals and impurities, the processed powdery illite 152 was side-packed into a sample holder and analyzed by X-ray diffraction (XRD) using a 153 Bruker/Siemens D5000 automated powder diffractometer using a $\mathrm{Cu} K \alpha$ radiation at $40 \mathrm{kV}$ and $15430 \mathrm{~mA}$ with a scan range of $2-40^{\circ} 2 \theta$, a scan speed of $0.02^{\circ} 2 \theta$ per $2 \mathrm{sec}$, and a step size of $0.02^{\circ}$ 
$1552 \theta$. The XRD pattern validates illite as the only clay mineral phase and trace quartz as an 156 impurity (Figure 1).

$158 \quad 2.2 \quad$ Preparation of clay mineral dispersions PSD measurements require the preparation of clay mineral dispersions either in air or 160 liquid. Table 2 summarizes the different methods employed to prepare clay mineral dispersions. 161 Details for each method are also provided as follows:

162 - I-A: To obtain the $<2 \mu \mathrm{m}$ fractions and hence their PSD, $0.2 \mathrm{~g}$ dry powder was first dispersed in $80 \mathrm{~mL}$ deionized (DI) water by using a Sonic Dismembrator Model 300 probe-type ultrasonic disruptor (Fisher Scientific, Pittsburgh, PA, USA) for 15 mins, followed by diluting with DI water to $1000 \mathrm{~mL}$ in a beaker. The resulting dispersion was allowed to settle for 3.5 hrs. The upper $5 \mathrm{~cm}$ supernatant was extracted as the $<2 \mu \mathrm{m}$ fraction for subsequent PSD measurement.

- I-B: To investigate the necessity of "overnight soaking" or "pre-equilibrating with water" that is usually required for sample preparation and hence its influence on PSD, $0.2 \mathrm{~g}$ dry clay mineral was used directly to prepare a dispersion or pre-soaked overnight (i.e., >16 hrs) before preparing a dispersion.

- I-C: To evaluate the effectiveness of mechanical disaggregation, $0.2 \mathrm{~g}$ overnight presoaked clay mineral was dispersed in $80 \mathrm{~mL}$ DI water by the aforementioned probe-type ultrasonic disruptor for 15 mins.

- I-D: To evaluate the influence of chemical dispersant, Na-hexametaphosphate (NaHMP; Mallinckrodt Baker Inc., Philipsburg, NJ, USA) solution at a concentration of $40 \mathrm{~g} / \mathrm{L}$ was used to replace DI water for dispersion preparation (ASTM, 2007). 
- I-E: To investigate the influence of swelling as a function of the dielectric constant of the dispersing solvents and the adsorbed exchangeable cations on the PSD of two montmorillonites, ethyl alcohol (EA; 190 Proof, Pharmco-AAPER, Brookfield, CT, USA), a glycerol (EMD Chemicals Inc., Darmstadt, Germany) solution in EA with a 2 vol.\% concentration (Kinter \& Diamond, 1958; Burt, 2004), and a glycerol solution in DI water with a 2 vol.\% concentration were used as solvents to prepare clay mineral dispersions.

- II: To evaluate the effectiveness of dry dispersion that may avoid the clay mineral-water interactions, four dry clay mineral powders were also dispersed in and transported by pressurized dry air.

In summary, air, water, EA, NaHMP, and glycerol were used as a dry dispersion medium, polar solvent, less polar solvent, chemical dispersant, and interlayer expanding agent, respectively, to prepare clay mineral dispersions so that the effectiveness of different dispersion methods can be evaluated.

\section{$2.3 \quad$ Methods}

All PSD measurements were conducted in a Cilas $1190^{\circledR}$ laser particle size analyzer (PSA) (Cilas Particle Size, Madison, WI, USA) under either wet or dry mode (Figure 2). In the wet mode, clay mineral dispersions at a concentration of $0.2 \mathrm{~g}$ dry clay mineral powder in $80 \mathrm{~mL}$ solvent prepared by the above methods were transferred to the PSA's liquid bath and then diluted to $500 \mathrm{~mL}$, which is the total volume of the PSA's closed-loop liquid circulation system (including the liquid bath and circulation tubes), followed by running a built-in ultrasound disperser beneath the liquid bath for $1.0 \mathrm{~min}$ to achieve better dispersion. To prevent unnecessary 
201 flocculation and settling, all clay mineral dispersions were continuously agitated by a pedal-like

202 stirrer located in the middle of the liquid bath at a constant speed of $180 \mathrm{rpm}$ and continuously

203 circulated in the PSA's circulation system by a peristaltic pump at a constant speed of $30 \mathrm{rpm}$,

204 while the PSD were continuously monitored by three laser beams. The pump resulted in an

205 average flow velocity of $0.15 \mathrm{~m} / \mathrm{s}$ and a Reynolds number of $\sim 1091$, which indicates one-

206 dimensional laminar flow inside the circulation tubes. Sufficient time (usually 15-20 mins) was

207 allowed for the circulating dispersions to reach a steady state (i.e., no further significant change

208 in the measured PSD even for prolonged circulation). After validating an equilibrated state, PSD

209 measurement was then conducted. Selective images of particles were also taken using a 3032

210 series preconfigured, inverted microscope (Accu-Scope ${ }^{\circledR}$ Inc., Commack, NY, USA) that is

211 externally connected to the PSA's liquid circulation system.

212 In the dry mode, dry powdery samples were placed in a vibrating mass distributor and

213 then transported and dispersed by pressurized dry air. Table 3 summarizes the selected dispersing

214 parameters (determined by trial and error) used for the four clay minerals, including vibration

215 frequency, vibration ratio, and air pressure.

216 For both modes, the laser diffraction data was analyzed using the Lorenz-Mie theory,

217 which is an exact description of the diffraction field. This theory is more accurate than the

218 Fraunhofer theory (an approximation of Lorenz-Mie theory) for PSD characterization of clay

219 minerals, especially when the sizes are close to the laser wave length of 635-830 nm (de Boer et 220 al., 1987). Particle size obtained by the PSA was defined as the diameter of equivalent spheres

221 calculated based on the volume moment mean value of multiple particles at a given size range.

222 That is: 


$$
D=\frac{\sum n l^{4}}{\sum n l^{3}}
$$

224 where $D$ is the mean diameter of all particles or flocs within a given size range, $n$ the number of 225 particles of a fixed size in the considered size range, and $l$ the diameter of a particle or floc.

$227 \quad 3 . \quad$ Results and discussion

$228 \quad 3.1 \quad P S D$ of the $<2 \mu \mathrm{m}$ fractions

The PSD curves of the $<2 \mu \mathrm{m}$ fractions (Figure 3) show that their particle size ranges from 0.04 (the practical particle size limit that this PSA apparatus can detect) to $\sim 4 \mathrm{~m}$ and more than $90-95 \%$ (by number) particles are $<2 \mu \mathrm{m}$. This is consistent with the purpose of ultrasound 232 disaggregation and subsequent settling (or fractionation) used to disperse clay mineral flocs and 233 remove impurities (e.g., quartz), which typically leaves only the $<2 \mu$ m individual clay mineral 234 particles in the supernatant (Chipera et al., 1993; Moore \& Reynolds, 1997; Chipera \& Bish, 235 2001; Furukawa et al., 2009). In fact, this also serves as an indirect and partial calibration of the 236 accuracy of the PSA.

237 Of the four clay minerals, kaolinite and illite exhibit a trimodal lognormal distribution 238 with the local maxima at $0.075,0.3$, and $1.2 \mu \mathrm{m}$ (Fig. 3b). The first one at $\sim 0.075 \mu \mathrm{m}$ is 239 extremely small with only $10-15 \%$ particles finer than this value. This range of sizes could be the 240 particle thickness and the laser measurements may only take place on a very small percentage of 241 clay mineral particles. The other two maxima represent the true basal plane dimensions of 242 kaolinite and illite, resulting in two aspect ratios of 16 and 4 for both clay minerals. Other studies 243 reported that this kaolinite has an aspect ratio of $~ 10$ (Zbik \& Smart, 2002) with an average of 2445.3 (Zbik \& Frost, 2009). In addition, some studies (e.g., (Mackinnon et al., 1993)) found that a 
245 similar kaolinite has two different sizes, $\sim 0.3$ and $\sim 1.2 \mu \mathrm{m}$, in its $<2 \mu \mathrm{m}$ fraction. The aspect 246 ratio of this illite has not been reported in the literature, but it can be reasonably assumed to have 247 similar values.

For the two montmorillonites, $\mathrm{Ca}^{2+}$-Mt exhibits a superimposed bimodal lognormal 249 distribution with two maxima at 0.6 and $\sim 1.5 \mu \mathrm{m}$, while $\mathrm{Na}^{+}-\mathrm{M}$ has a monomodal distribution 250 with a maximum at $1.5 \mu \mathrm{m}$. Such different PSD stem from their different chemical 251 compositions and distinct swelling behavior. According to their chemical formulas (Table 1), 252 both clay minerals can be regarded as a mixed $\mathrm{Ca}^{2+} / \mathrm{Na}^{+}-\mathrm{Mt}$, but with different mole ratios of $253 \mathrm{Ca}^{2+} / \mathrm{Na}^{+}$(i.e., 27/4 and 3/8 for the $\mathrm{Ca}^{2+}-\mathrm{Mt}$ and $\mathrm{Na}^{+}-\mathrm{Mt}$, respectively). As reported by (Laird, 254 2006), during swelling in water, cation demixing in montmorillonite occurs so that $\mathrm{Na}^{+}{\text {and } \mathrm{Ca}^{2+}}^{2+}$ 255 are separated and relocated into different interlayers. The basal spacing, $d(001)$, of $\mathrm{Na}^{+}-$ 256 dominated interlayers can swell to >9 nm (Posner \& Quirk, 1964; Olejnik et al., 1974), while 257 that of $\mathrm{Ca}^{2+}$-dominated interlayers only swells to $<1.9 \mathrm{~nm}$ (Theng, 1982). When mechanically 258 dispersed by a probe-type ultrasound disruptor, the swollen montmorillonite particles readily 259 break apart or exfoliate at the interlayers dominated by $\mathrm{Na}^{+}$, leading to the formation of two 260 types of particles (Figure 4): (1) $1.0 \mathrm{~nm}$ thick, $\mathrm{Na}^{+}$-based individual 2:1 layers as single 261 particles, and (2) particles with $\mathrm{Ca}^{2+}$ as the dominant interlayer cations. The latter are stacks of 262 parallel 2:1 layers (Quirk \& Aylmore, 1971; Kleijn \& Oster, 1982), which are relatively stable 263 under shaking, stirring, sonication, and even certain pressure (Kjellander et al., 1988; Yariv \& 264 Lapides, 2003; Laird, 2006). For both $\mathrm{Ca}^{2+}-\mathrm{Mt}$ and $\mathrm{Na}^{+}-\mathrm{Mt}$, the process of $3.5 \mathrm{hr}$ sedimentation 265 can eliminate those relatively large $\mathrm{Ca}^{2+}-\mathrm{Mt}$ swollen particles (i.e., they readily settle down 266 faster), resulting in a supernatant containing the relatively smaller swollen particles and 267 exfoliated 2:1 layers. As the major particles in the $\mathrm{Na}^{+}$-Mt supernatant, the very thin, flexible, 
268 and soft (Bihannic et al., 2001) $\mathrm{Na}^{+}$-based individual 2:1 layers can easily curl and form 269 irregularly shaped particles in the PSA's circulation system, which yields a monomodal

270 distribution for the $\mathrm{Na}^{+}-\mathrm{Mt}$. However, for the $\mathrm{Ca}^{2+}-\mathrm{Mt}$, the extracted supernatant may contain

271 both relatively smaller $\mathrm{Ca}^{2+}$-Mt swollen particles and $\mathrm{Na}^{+}$-based individual 2:1 layers (Lagaly, 272 2006), resulting in a bimodal distribution.

273

$274 \quad 3.2 \quad$ Effect of overnight soaking in water

275 Figure 5 compares the PSD of the DI water-soaked vs. unsoaked samples for the four 276 clay minerals. All curves show a maximum size of 30-60 $\mu \mathrm{m}$. The two non-swelling clay 277 minerals, kaolinite and illite, exhibit a trimodal distribution with three maxima at 0.3, 1.5-2.5, 278 and $13-20 \mu \mathrm{m}$, while the two swelling clay minerals, $\mathrm{Ca}^{2+}-\mathrm{Mt}$ and $\mathrm{Na}^{+}-\mathrm{Mt}$, have a bimodal 279 distribution with local maxima at 2.1-2.5 and 13-16 $\mu \mathrm{m}$. The PSD value of the soaked kaolinite 280 is in agreement with that of another similar kaolinite (KGa-1) reported by (Franco et al., 2004). 281 For all samples, the two maxima at smaller sizes (e.g., $<10 \mu \mathrm{m}$ ) of water-soaked sample (Figure 282 5) are almost at the same locations as those from the $<2 \mu \mathrm{m}$ fractions (Figure 3), indicating that 283 they are caused by dispersed, primary clay mineral particles. The third maximum located 284 between $10-20 \mu \mathrm{m}$ is not observed in the $<2 \mu \mathrm{m}$ fractions. As reported in the literature (Lee et al., 285 2012), flocculi, the smallest clay mineral-based aggregates of $10-20 \mu \mathrm{m}$ in size, are relatively 286 strong and hence hardly break down to the primary clay mineral particles (Vandeven \& Hunter, 287 1977). In addition, impurities (e.g., quartz) may also contribute to this peak (Pruett \& Webb, 288 1993). Figures 6a to 6d show some representative optical microscope images of soaked clay 289 mineral samples. The particle sizes observed from these images are consistent with the above 
290 analysis. For instance, $\mathrm{Ca}^{2+-}$-Mt has larger flocculi than other samples, while illite has the 291 smallest flocculi.

Except kaolinite, the PSD of the soaked and un-soaked samples of the other three clay minerals are identical, indicating that the PSD of these three clay minerals with relatively higher layer charges are not sensitive to overnight soaking. For kaolinite, overnight soaking shifts the

295 cumulative PSD curve toward the left, or makes the PSD finer, as indicated by the change in the 296 $D_{50}$ from 16 to $4 \mu \mathrm{m}$ for the unsoaked and soaked samples, respectively. This well-crystallized 297 kaolinite has low defects (Pruett \& Webb, 1993), with very low but opposite electrical charges of $298-0.17$ and +0.11 in the tetrahedral and octahedral sheets per $\mathrm{O}_{10}(\mathrm{OH})_{8}$, respectively (Table 1). 299 The kaolinite dispersion has a measured pH 5.97 (Table 1). Under such a slightly acidic 300 condition, the outmost octahedral sheet (as one face surface) is positively charged, while the 301 outmost tetrahedral sheet (as the other face surface) is negatively charged (Gupta et al., 2011). 302 As such, the electrical field generated by charges on face surfaces is very weak and there is also 303 a weak electrostatic attraction between the octahedral face surface of one particle and the 304 tetrahedral face of the other particle. Therefore, it may take a relatively long time for kaolinite 305 particles to reach a fully hydrated and dispersed state. In contrast, illite, $\mathrm{Ca}^{2+}-\mathrm{Mt}$, and $\mathrm{Na}^{+}-\mathrm{Mt}^{2}$ 306 have relatively higher electrical charges of same polarity on face surfaces (Table 1), resulting in 307 a stronger electrical field generated by the face surface as well as a stronger electrostatic 308 repulsion between the face surfaces of individual particles. As such, they can hydrate quickly and 309 a fully hydrated clay mineral particle facilitates subsequent dispersion. In addition, compared 310 with the kaolinite dispersion of the same concentration (e.g., $0.4 \mathrm{~g} / \mathrm{L}$ ), the much higher specific 311 surface area (SSA) of the other three clay minerals renders them a larger surface density (i.e., 312 total surface area per unit volume of dispersion) for particle-particle interactions, which may 
313 facilitate a quicker hydration and dispersion (Quirk \& Aylmore, 1971; Rengasamy et al., 1976;

314 Kleijn \& Oster, 1982; Laird, 2006).

315 In summary, although overnight soaking is recommended as a routine step to prepare clay

316 mineral dispersions for particle size analysis, its necessity or influence has rarely been reported.

317 Based on the above analysis, prolonged soaking is necessary for clay minerals with small layer

318 charges, such as kaolinite. Although this step may not be very important for highly charged clay

319 minerals, it is still a good practice to perform this step for most PSD measurements.

$321 \quad 3.3 \quad$ Effect of dispersion methods

Figure 7 shows the PSD of the four clay minerals treated by different dispersion methods,

323 including overnight soaking, NaHMP dispersion, ultrasound (US) dispersion, and dry dispersion

324 in air (Dry). The most striking feature is that, compared with dispersion methods in the liquid

325 mode, the PSD curves obtained in the dry mode lie on the rightmost for all four clay minerals,

326 indicating that much coarser particles or aggregates exist in the air-dispersed samples or, in other

327 words, the samples are not well dispersed. The frequency distribution curves show four major

328 peaks, with the largest one at $40-320 \mu \mathrm{m}$. In this mode, pressurized dry air is used as both a

329 solvent for transporting and floating clay mineral particles and a mechanical disaggregation tool,

330 which is hoped to eliminate the influence of complex clay mineral-water interactions on PSD

331 measurements. However, it is known that air-dried clay minerals still contain some water

332 adsorbed from the moisture in air, and hence clay mineral particles can still interact with each

333 other to form aggregates via clay mineral-water interactions (e.g., van der Waals attraction,

334 hydration, capillary, and Coulomb force). In addition, the air-dispersed clay mineral in dry mode

335 is not circulated in a closed-loop system in the PSA, but is quickly transported through the laser 
336 measurement window. Therefore, an equilibrium state may not be reached during the

337 measurement. In conclusion, dry dispersion cannot be employed to characterize the PSD of 338 source clay minerals.

339 For other dispersion methods in liquid mode, all four clay minerals show a trimodal, 340 lognormal distribution with a size range of 0.04-50 $\mu \mathrm{m}$. The three maxima are at 0.3-0.6, 2, and $341 \sim 13 \mu \mathrm{m}$. Again, the former two represent primary clay mineral particles, while the last is caused 342 by clay mineral flocculi. The effect of chemical dispersion and ultrasound disaggregation on 343 each clay mineral's PSD is further discussed separately below.

\section{$344 \quad 3.3 .1 \quad$ Kaolinite}

Compared with the water-soaked sample, both chemical and mechanical dispersions generate finer PSD, although the latter even results in a higher population of $<1 \mu \mathrm{m}$ particles.

347 This result is consistent with others in the literature (Crowley \& Welch, 1954; Genrich \& 348 Bremner, 1972b, a). As mentioned above, the two face surfaces (i.e., one is the outmost 349 tetrahedral sheet, and the other is the outmost octahedral sheet) with opposite, low charges can 350 generate electrostatic attraction between the basal planes of two different particles, leading to the 351 formation of flocs. Another reason for floc formation is that kaolinite's edge charge is positive at $352 \mathrm{pH}<7$ (i.e., a pH 5.97 was measured) and the interaction of positively charged edge to negatively 353 charged tetrahedral face can also contribute to flocculation (Du et al., 2010). However, kaolinite 354 has very low layer charges, which means that the electrostatic attraction is not very strong, and 355 hence kaolinite flocs can be dispersed by ultrasonic dispersion. Chemical dispersion by NaHMP 356 is achieved by the edge charge reversal through adsorption of $\mathrm{PO}_{3}{ }^{-}$.

$357 \quad 3.3 .2 \quad$ Illite 
The cumulative PSD curve obtained by the ultrasound disaggregation lies in the leftmost, 359 while that by chemical dispersant just overlays with the one of soaked sample (Figure 7b). This 360 suggests that NaHMP dispersion is not effective for illite. Two reasons may possibly contribute 361 to this: (1) illite possesses a very high layer charge (e.g., -1.68 for this sample, Table 1) and (2) 362 the amount of used dispersant may not be enough to reverse the edge charges, indicating that the 363 NaHMP concentration may be too low for illite. Therefore, for the highly charged, non-swelling 364 illite, chemical dispersion by NaHMP is not as effective as ultrasound dispersion.

$365 \quad 3.3 .3 \quad \mathrm{Ca}^{2+}-\mathrm{Mt}$

366 According to the relative locations of the cumulative PSD curves (Figure 7c), chemical 367 dispersion is more effective than ultrasound dispersion, although both methods yield finer 368 particles than soaking. Moreover, ultrasound dispersion generates more $<1 \mu \mathrm{m}$ particles, while 369 chemical dispersion yields more $>1 \mu$ m particles. The chemical dispersant, NaHMP, may alter 370 the particle sizes in two ways: (1) it can partly reverse the clay mineral's positive edge charges 371 by $\left(\mathrm{PO}_{3}{ }^{-}\right)_{6}$ and hence reduce the tendency of aggregation via edge-face interactions (Levy et al., 372 1991) and (2) the added $\mathrm{Na}^{+}$can exchange with the interlayer $\mathrm{Ca}^{2+}$, resulting in a change of $\mathrm{Ca}^{2+}$ 373 Mt to $\mathrm{Na}^{+}-\mathrm{Mt}$ that can swell further and then exfoliate into smaller particles (as discussed 374 previously). Therefore, adding the dispersant, NaHMP, to $\mathrm{Ca}^{2+}-\mathrm{Mt}$ may generate misleading 375 PSD results because of the partial conversion of $\mathrm{Ca}^{2+}-\mathrm{Mt}$ to $\mathrm{Na}^{+}-\mathrm{Mt}$.

$376 \quad 3.3 .3 \quad \mathrm{Na}^{+}-\mathrm{Mt}$

377 It appears that either ultrasound dispersion or overnight soaking can yield the finest PSD 378 for $\mathrm{Na}^{+}-\mathrm{Mt}$, although the former can generate more $<1 \mu \mathrm{m}$ particles. Chemical dispersion causes 379 the presence of more $>1 \mu$ m particles. Therefore, NaHMP is not effective for dispersing this $\mathrm{Na}^{+}-$ 

397 minerals.

Mt. Similar observations have been reported in the literature. For instance, (Frenkel et al., 1992) stated that NaHMP is less effective in dispersing $\mathrm{Na}^{+}-\mathrm{Mt}$ than kaolinite.

Finally, it is noteworthy to further discuss the effectiveness of ultrasonic dispersion. For all four clay minerals, the population of the smallest primary particles (i.e., $<1-2 \mu \mathrm{m}$ ) obtained by ultrasound dispersion is the highest of all dispersion methods, indicating that this mechanical disaggregation method helps breakdown clay mineral flocs. Ultrasound dispersion, by creating and fracturing microbubbles in an aqueous medium, results in a sudden energy release, which generates locally high temperature, high pressure, and strong shock waves to help disperse, expand, or split clay mineral particles (Lapides \& Yariv, 2004; Zhang et al., 2010). Thus, the microprobe-type ultrasonication indeed facilitates the swelling and exfoliation of the two montmorillonites. As reported by Franco et al. (2004), ultrasound can cause both exfoliation and size reduction in other particle dimensions. As such, for the non-swelling kaolinite and illite, and limited swelling $\mathrm{Ca}^{2+}$-Mt, the ultrasound processed samples show a size reduction in all size ranges when compared with their corresponding soaked samples. This reduction can be attributed to either particle delamination (e.g., as for $\mathrm{Ca}^{2+}-\mathrm{Mt}$ ) or breakdown of clay mineral particles into smaller sizes (as measured along the basal plane dimension) or both. While the former can occur only in the two montmorillonites, the latter may happen in all four clay

\subsection{Effect of different solvents for swelling clay minerals}

Figure 8 shows the PSD of the two montmorillonites dispersed in DI water, EA, a 400 glycerol in DI water solution (Gly-DI), and a glycerol in EA solution (Gly-EA). The PSD 401 obtained from the water-soaked samples are used as a reference for comparison. For all four 402 solvents, both $\mathrm{Ca}^{2+}-\mathrm{Mt}$ and $\mathrm{Na}^{+}-\mathrm{Mt}$ exhibit a bimodal lognormal distribution with a size range of 
0.1 to $70 \mu \mathrm{m}$ and two maxima at $\sim 2.2-2.5$ and $\sim 13-15 \mu \mathrm{m}$ for primary particles and flocculi,

404 respectively. Moreover, the PSD change in $\mathrm{Ca}^{2+}-\mathrm{Mt}$ caused by different solvents is not as 405 significant as that in $\mathrm{Na}^{+}-\mathrm{Mt}$.

406 For $\mathrm{Ca}^{2+}$-Mt, although the PSD dependence on the type of solvent is not so significant, 407 some changes in PSD are still discernable. Of the four solvents, the Gly-EA yields the coarsest 408 PSD, while water generates the finest PSD. Also, the Gly-DI yields a coarser PSD than the DI 409 water, and the PSD obtained from the EA is finer than that from Gly-EA, but coarser than that 410 from DI water. The dielectric constant of water, EA, and glycerol at $20-25{ }^{\circ} \mathrm{C}$ is $80.3,24.3$, and 411 42.5, respectively (Table 4). If the interlayer of $\mathrm{Ca}^{2+}-\mathrm{Mt}$ is filled with EA (to replace water), the 412 Coulomb attraction between the interlayer exchangeable cations (i.e., $\mathrm{Ca}^{2+}$ ) and negatively 413 charged 2:1 layers will be much stronger, thus preventing the $\mathrm{Ca}^{2+}$-Mt from swelling. In fact, 414 neither $\mathrm{Ca}^{2+}$-Mt nor $\mathrm{Na}^{+}-\mathrm{Mt}$ swells in pure alcohol (Brindley et al., 1969). For $\mathrm{Ca}^{2+}-\mathrm{Mt}^{2}$, the 415 difference between the PSD in water and in EA is not significant, even though the clay mineral 416 swells in water but not in pure EA. This can be reasoned by the fact that the increase in particle 417 size caused by swelling in water is counterbalanced by the decrease in particle size caused by 418 exfoliation, which in turn is promoted by the existence of $\mathrm{Na}^{+}$in some interlayers (as discussed 419 previously) and flow-induced shearing (causing exfoliation)

420 It is also interesting to discuss the influence of glycerol as an expanding agent on PSD 421 (Figure 8). Glycerol is completely soluble in water and alcohol. According to (Kinter \& 422 Diamond, 1958), glycerol molecules can enter the interlayer space of montmorillonite and easily 423 form a stable glycerol complex without heating. The basal spacing $d(001)$ for montmorillonite 424 with two layers of glycerol, monolayer of glycerol, and absence of glycerol as its interlayer is $4251.84,1.42$, and $0.99 \mathrm{~nm}$, respectively. The partial replacement of water molecules by larger 
426 glycerol molecules in the interlayer may further increase repulsive interlayer force (Brindley et 427 al., 1969), which results in an increase in swollen particle's basal spacing and hence the particle 428 size. As shown in Figure 8, the Gly-DI slightly increases the size of particles within the size 429 range of $\sim 1-10 \mu \mathrm{m}$, but without the change in the mean particle size $\left(D_{50}\right)$, when compared with 430 the PSD from DI water. The Gly-EA can further increase the particle sizes, with a change in $D_{50}$ 431 from 12 to $17 \mu \mathrm{m}$. In the Gly-EA solvent, montmorillonite's basal spacing increases by 432 intercalating glycerol molecules into its interlayer space, which causes the size increases (i.e., 433 when compared with the DI water as a solvent). Again, due to the smaller dielectric constants of 434 both glycerol and EA, the interlayer attraction force is stronger in the Gly-EA solvent than in 435 water, and hence the swollen montmorillonite particles cannot be easily exfoliated by hydraulic 436 shearing force. Therefore, there are two reasons why the PSD in the Gly-EA is much coarser 437 than in the DI water: (1) particle swelling due to the intercalation of glycerol and (2) less 438 hydraulic shear-induced particle exfoliation.

439 For $\mathrm{Na}^{+}-\mathrm{Mt}$, the PSD dependence on different solvents is more significant (Figure 8b).

440 The four PSD curves can be separated into two groups: DI water and Gly-DI as the first group, 441 and EA and Gly-EA as the second group. The difference in PSD within each of the two groups is 442 very small. As mentioned above, $\mathrm{Na}^{+}$-Mt can swell to infinity in water, and hence an individual 443 2:1 layer is a particle. Moreover, glycerol can be intercalated into $\mathrm{Na}^{+}-\mathrm{Mt}$ 's interlayers. For $\mathrm{Na}^{+}-$ 444 dominated interlayers, glycerol intercalation causes exfoliation, resulting in a decrease in size, 445 while for $\mathrm{Ca}^{2+}$ or $\mathrm{K}^{+}$-dominated interlayers, glycerol intercalation further expands basal spacing 446 but will not cause exfoliation, resulting in an increase in size. Therefore, the Gly-DI yields a 447 slightly coarser PSD than DI water. 
For the second group where EA and Gly-EA are used as solvents, $\mathrm{Na}^{+}-\mathrm{Mt}$ does not 449 readily swell in EA. As such, $\mathrm{Na}^{+}-\mathrm{Mt}$ in EA exhibits much coarser PSD than in DI water. In fact, 450 its $D_{50}$ increases from $\sim 2.2 \mu \mathrm{m}$ in water to $\sim 13 \mu \mathrm{m}$ in EA. Because $\mathrm{Na}^{+}$-Mt swells in the Gly-EA 451 by intercalating glycerol (but probably not EA), some of which can be exfoliated into smaller 452 particles by hydraulic shearing, resulting in finer PSD in the Gly-EA than in EA. However, due 453 to the smaller dielectric constants of glycerol and EA (Table 4), which results in stronger 454 interlayer Coulomb attraction force (between interlayer cations and 2:1 layers), the exfoliation 455 can be very limited, and hence the change in the PSD is very small.

The PSD dependence on different levels of clay mineral swelling in different solvents is

457 also demonstrated by the images shown in Figure 6. Both the $\mathrm{Ca}^{2+}-\mathrm{Mt}$ and $\mathrm{Na}^{+} \mathrm{Mt}$ in EA (Figure 458 6e and 6f) exhibit larger particles than in DI water, because they can swell in water and 459 subsequently exfoliate into smaller particles (Figure 6c and 6d).

460

$461 \quad 3.5 \quad$ Intrinsic PSD of the four clay minerals

462 As pointed out earlier, intrinsic PSD should be obtained from the sample dispersions 463 consisting of only primary particles, and should truly represent the sizes of original, physically 464 individual particles that are not affected by sample preparation, such as chemical dispersants, 465 excessive physical disruption or disaggregation, or solvent-clay mineral interactions, nor affected 466 by aggregation or flocculation in the prepared clay mineral dispersions. Strictly speaking, 467 because of the presence of flocculi, a kind of clay mineral aggregates, it is difficult to obtain the 468 intrinsic PSD of the four source clay minerals. However, if the 10-20 $\mu \mathrm{m}$ flocculi are treated as 469 inherent to the clay minerals, the above analyses can be used to find their intrinsic PSD, as 470 discussed below. 
For the non-swelling kaolinite and illite, although ultrasound dispersion yields the finest

472 PSD (Figure 7), it may also cause particle disruption or breakage along the basal plane

473 dimension or delamination along the $c$-axis. Thus the obtained PSD are not intrinsic. The

474 difference in the PSD from NaHMP dispersion and overnight soaking is not so significant for

475 illite, but there is difference for kaolinite. Therefore, it is reasonably to conclude that the

476 kaolinite PSD obtained by NaHMP dispersion represents the intrinsic one and the illite PSD

477 obtained by overnight soaking or NaHMP is intrinsic.

$478 \quad$ For the swelling clay minerals, primary particles should be the individual particles at their 479 non-swollen state. The PSD obtained in water-based dispersions (e.g., DI water, NaHMP 480 solution, glycerol in water solution) also reflect the swollen particles. Additionally, powdery clay 481 minerals cannot be fully dispersed in dry mode. The use of an interlayer expanding agent, 482 glycerol, certainly alters the original particle thickness. Therefore, the PSD of the two 483 montmorillonites dispersed in ethyl alcohol, a much less polar liquid where they do not readily 484 swell, are regarded as intrinsic. This is due to the fact that dispersion in a less polar liquid avoid 485 swelling (due to intercalation of water molecules into interlayers), cation exchange between the 486 clay mineral and solution, and exfoliation. Table 5 summarizes the intrinsic PSD parameters for 487 all four clay minerals.

488

$489 \quad 3.6 \quad$ Practical implications

$490 \quad$ PSD are one of the most fundamental physical properties of soils. It is required by current 491 soil classification standards (e.g., the unified soil classification system). Based on the above 492 analyses, relatively strong clay mineral-based flocculi of $10-20 \mu \mathrm{m}$ in size are quite resistant to 493 mechanical disaggregation and chemical dispersion and can exist in different types of clay 
494 minerals. As such, this type of clay mineral aggregates is usually counted toward the silt-sized 495 fraction, which may lead to misleading soil classifications or incorrect soil properties (e.g., 496 activity). On the other hand, better dispersion techniques that can disaggregate clay mineral 497 flocculi should be developed in future studies.

In addition, several other factors warrant more thorough considerations when selecting 499 appropriate sample preparation methods for PSD analysis. First, soaking in water for sufficient 500 time (e.g., overnight) should be always performed for most soils, especially those containing a 501 significant fraction of kaolinite or other low charge clay minerals; Second, caution should be 502 taken when $\mathrm{Na}^{+}$-based dispersants are used, particularly for soils with non-sodium based 503 smectites, although NaHMP is specified in the ASTM or other standard methods for PSD 504 analysis. As a general guideline, when selecting proper dispersants for soils containing Ca or 505 other divalent cation dominant smectites, cation exchange between smectites and dissolved 506 dispersants that can lead to alteration to the particle size should be avoided; Finally, the solvent 507 used to prepare soil dispersions should not be limited to water only, and other polar or less polar 508 liquids may also be selected to prevent the unnecessary clay mineral-water or clay mineral509 solvent interactions.

510

\section{$511 \quad 4 . \quad$ Conclusions}

An experimental study was conducted to evaluate the PSD and their variability of four

513 source clay minerals, kaolinite, illite, $\mathrm{Ca}^{2+}-\mathrm{Mt}$, and $\mathrm{Na}^{+}-\mathrm{Mt}$, under different dispersion methods,

514 including dry dispersion in pressurized air and wet dispersion in water and EA with and without 515 an interlayer expanding agent, glycerol, along with ultrasound disaggregation and NaHMP 516 dispersion. Based on the results and above discussion, the following conclusions can be drawn: 
- Overnight soaking in water should always be included in the preparation of clay mineral dispersions for PSD analysis, especially for kaolinite or other low charge clay minerals.

- Prolonged ultrasound disaggregation should be avoided in sample preparation for PSD measurement in order to prevent unnecessary particle exfoliation.

- Dry dispersion in pressurized air is not effective to disperse clay mineral aggregates for PSD analysis.

- A much less polar solvent such as EA should be used to prepare the dispersions of swelling clay minerals for PSD analysis.

- Most clay minerals contain relatively strong clay mineral-based flocculi of $10-20 \mu \mathrm{m}$ in size that is resistant to disaggregation, and hence the resulting PSD overestimate the siltsized fraction, but underestimate the clay-sized fraction.

- The intrinsic PSD of kaolinite and illite should be obtained by NaHMP dispersion, while those of the two smectites can be obtained by dispersing in EA or other less- or non-polar solvents.

- In general, caution should be taken in selecting an appropriate chemical dispersant for PSD analysis, especially when selecting a $\mathrm{Na}^{+}$-based dispersant for soils containing nonsodium based smectites.

- The PSD of most clay minerals show a multimodal lognormal distributions with local maxima representing $<2 \mu \mathrm{m}$ primary clay mineral particles, $10-20 \mu \mathrm{m}$ flocculi, and sometimes 50-500 $\mu \mathrm{m}$ microflocs.

\section{Notations:}

$\theta$ - Diffraction angle

$D$ - Volume moment based mean diameter of particles within a given size range 
$n$ - Number of particles

$l$ - Diameter of a particle in that given size range

$d$ - Basal spacing of clay minerals

$P$ - Percent finer of particles by number

$F$ - Frequency as a percentage of a particle in the whole sample

\section{Acknowledgments}

This work was partially supported by the Office of Naval Research through Naval Research Laboratory base funding under Award No. N00173-10-1-G013 as part of the NRL ARI "Biogeochemical Influences on Cohesive Sediment Strength in Marine and Estuarine Environments (PE No. 061153N)". The facilities used in this study were purchased using the fund from the Louisiana Board of Regents Enhancement Program.

\section{REFERENCES}

Anderson, R.L., Ratcliffe, I., Greenwell, H.C., Williams, P.A., Cliffe, S. \& Coveney, P.V. (2010) Clay swelling - a challenge in the oilfield. Earth-Science Reviews, 98, 201-216.

ASTM. (2007) Standard test method for particle-size analysis of soils. Pp. D422-463, ASTM International, West Conshohocken, PA.

Bihannic, I., Tchoubar, D., Lyonnard, S., Besson, G. \& Thomas, F. (2001) X-ray scattering investigation of swelling clay fabric: 1 . The dry state. Journal of Colloid and Interface Science, 240, 211-218.

Brindley, G.W., Wiewiora, K. \& Wiewiora, A. (1969) Intracrystalline swelling of montmorillonite in some water-organic mixtures (clay-organic studies. Xvii). American Mineralogist, 54, 1635-1644.

Burt, R. (2004) Soil survey laboratory methods manual. Pp. 735, 42, Soil Survey Investigations Report No. 42 Version 4.0, Lincoln, NE: Natural Resources Conservation Service, U.S. Department of Agriculture.

Celis, R. \& Koskinen, W.C. (1999) Sorption and desorption of triadimefon by soils and model soil colloids. Journal of Agricultural and Food Chemistry, 47, 776-781. 
Chipera, S.J. \& Bish, D.L. (2001) Baseline studies of the clay minerals society source clays: Powder x-ray diffraction analyses. Clays and Clay Minerals, 49, 398-409.

Chipera, S.J., Guthrie, G.D. \& Bish, D.L. (1993) Preparation and purification of mineral dusts. Reviews in Mineralogy, 28, 235-249.

Costanzo, P.M. (2001) Baseline studies of the clay minerals society source clays: Introduction. Clays and Clay Minerals, 49, 372-373.

Crowley, M.S. \& Welch, A.P. (1954) Clay-particle dispersion by ultrasounds. Journal of The American Ceramic Society, 37, 433-439.

Daoud, Y. \& Robert, M. (1992) Influence of particle size and clay organization on hydraulic conductivity and moisture retention of clays from saline soils. Applied Clay Science, 6, 293299.

de Boer, G.B., de Weerd, C., Thoenes, D. \& Goossens, H.W. (1987) Laser diffraction spectrometry: Fraunhofer diffraction versus mie scattering. Particle Characterization, 4, 1419.

Du, J., Morris, G., Pushkarova, R.A. \& Smart, R.S. (2010) Effect of surface structure of kaolinite on aggregation, settling rate, and bed density. Langmuir, 26, 13227-13235.

Franco, F., Perez-Maqueda, L.A. \& Perez-Rodriguez, J.L. (2004) The effect of ultrasound on the particle size and structural disorder of a well-ordered kaolinite. Journal of Colloid and Interface Science, 274, 107-117.

Frenkel, H., Levy, G.J. \& Fey, M.V. (1992) Clay dispersion and hydraulic conductivity of claysand mistures as affected by the addition of vairous anions. Clays and Clay Minerals, 40, 515-521.

Furukawa, Y., Watkins, J.L., Kim, J., Curry, K.J. \& Bennett, R.H. (2009) Aggregation of montmorillonite and organic matter in aqueous media containing artificial seawater. Geochemical Transactions, 10.

Genrich, D.A. \& Bremner, J.M. (1972a) Effect of probe condition on ultrasonic dispersion of soils by probe-type ultrasonic vibrators. Soil Sci. Soc. Am. Proc., 36, 975-976.

-. (1972b) A reevaluation of the ultrasonic-vibration method of dispersing soils. Soil Sci. Soc. Am. Proc., 36, 944-947.

Goldberg, S., Forster, H.S. \& Godfrey, C.L. (1996) Molybdenum adsorption on oxides, clay minerals, and soils. Soil Science Society of America Journal, 60, 425-432.

Gupta, V., Hampton, M.A., Stokes, J.R., Nguyen, A.V. \& Miller, J.D. (2011) Particle interactions in kaolinite suspensions and corresponding aggregate structures. Journal of Colloid and Interface Science, 359, 95-103. 
Güven, N. (1992) Molecular aspects of clay-water itneractions. Pp. In N. Güven, and R. Pollastro, Eds. Clay-water interface and its rheological implications, CMS workshop lectures, 4, Clay Minerals Society.

Harvey, C.C. \& Murray, H.H. (1997) Industrial clays in the 21st century: A perspective of exploration, technology and utilization. Applied Clay Science, 11, 285-310.

Helmy, A.K. (1998) The limited swelling of montmorillonite. Journal of Colloid and Interface Science, 207, 128-129.

Hill, P.S. (1998) Controls on floc size in the sea. Oceanography, 11, 13-18.

Hower, J. \& Mowatt, T.C. (1966) The mineralogy of illites and mixed-layer illite/montmorilonites. American Mineralogist, 51, 825-854.

Jouyban, A., Soltanpour, S. \& Chan, H.K. (2004) A simple relationship between dielectric constant of mixed solvents with solvent composition and temperature. International Journal of Pharmaceutics, 269, 353-360.

Kiliaris, P. \& Papaspyrides, C.D. (2010) Polymer/layered silicate (clay) nanocomposites: An overview of flame retardancy. Progress in Polymer Science, 35, 902-958.

Kinter, E.B. \& Diamond, S. (1958) Gravimetric determination of monolayer glycerol complexes of clay minerals. Clays and Clay Minerals, 5, 318-333.

Kjellander, R., Marcelja, S., Pashley, R.M. \& Quirk, J.P. (1988) Double-layer ion correlation forces restrict calcium clay swelling. Journal of Physical Chemistry, 92, 6489-6492.

Kleijn, W.B. \& Oster, J.D. (1982) A model of clay swelling and tactoid formation. Clays and Clay Minerals, 30, 383-390.

Lagaly, G. (2006) Chapter 5. Colloid clay science. Pp. 141-245. In B.K.G.T. Faïza Bergaya, and L. Gerhard, Eds. Developments in clay science, Volume 1, Elsevier.

Lagaly, G. \& Ziesmer, S. (2003) Colloid chemistry of clay minerals: The coagulation of montmorillonite dispersions. Advances in Colloid and Interface Science, 100, 105-128.

Laird, D.A. (2006) Influence of layer charge on swelling of smectites. Applied Clay Science, 34, 74-87.

Lapides, I. \& Yariv, S. (2004) The effect of ultrasound treatment on the particle-size of wyoming bentonite in aqueous suspensions. Journal of Materials Science, 39, 5209-5212.

Lee, B.J., Fettweis, M., Toorman, E. \& Molz, F.J. (2012) Multimodality of a particle size distribution of cohesive suspended particulate matters in a coastal zone. Journal of Geophysical Research-Oceans, 117, 17.

Levy, G.J., Shainberg, I., Alperovitch, N. \& Vandermerwe, A.J. (1991) Effect of nahexametaphosphate on the hydraulic conductivity of kaolinite-sand mistures. Clays and Clay Minerals, 39, 131-136. 
662

663

664 665

666 667

668 669

670 671

Mackinnon, I.D.R., Uwins, P.J.R., Yago, A. \& Page, D. (1993) Kaolinite particle sizes in the $<2$ micron range using laser scattering. Clays and Clay Minerals, 41, 613-623.

Moore, D.M. \& Reynolds, R.C. (1997) X-ray diffraction and the identification and analysis of clay minerals. Pp. 378, Oxford University Press, New York.

Murray, H.H. (1999) Applied clay mineralogy today and tomorrow. Clay Minerals, 34, 39-49.

-. (2000) Traditional and new applications for kaolin, smectite, and palygorskite: A general overview. Applied Clay Science, 17, 207-221.

Neumann, M.G., Gessner, F., Schmitt, C.C. \& Sartori, R. (2002) Influence of the layer charge and clay particle size on the interactions between the cationic dye methylene blue and clays in an aqueous suspension. Journal of Colloid and Interface Science, 255, 254-259.

Olejnik, S., Posner, A.M. \& Quirk, J.P. (1974) Swelling of montmorillonite in polar organic liquids. Clays and Clay Minerals, 22, 361-365.

Pavlidou, S. \& Papaspyrides, C.D. (2008) A review on polymer-layered silicate nanocomposites. Progress in Polymer Science, 33, 1119-1198.

Posner, A.M. \& Quirk, J.P. (1964) Changes in basal spacing of montmorillonite in electrolyte solutions. Journal of Colloid Science, 19, 798-812.

Pruett, R.J. \& Webb, H.L. (1993) Sampling and analysis of kga-1b well-crystallized kaolin source clay. Clays and Clay Minerals, 41, 514-519.

Quirk, J.P. \& Aylmore, L.A.G. (1971) Domains and quasi-crystalline regions in clay systems. Soil Science Society of America Proceedings, 35, 652-654.

Rengasamy, P., van Assche, J.B. \& Uytterhoeven, J.B. (1976) Particle size of wyoming bentonite and its relation to the cation exchange capacity and the homogeneity of the charge density. Journal of the Chemical Society, Faraday Transactions 1: Physical Chemistry in Condensed Phases, 72, 376-381.

Segad, M., Jonsson, B., Akesson, T. \& Cabane, B. (2010) Ca/na montmorillonite: Structure, forces and swelling properties. Langmuir, 26, 5782-5790.

Theng, B.K.G. (1982) Clay-polymer interactions - summary and perspectives. Clays and Clay Minerals, 30, 1-10.

Vandeven, T.G.M. \& Hunter, R.J. (1977) Energy-dissipation in sheared coagulated sols. Rheologica Acta, 16, 534-543.

Walling, D.E. \& Moorehead, P.W. (1989) The particle size characteristics of fluvial suspended sediment: An overview. Hydrobiologia, 176/177, 125-149.

Wu, W.J. (2001) Baseline studies of the clay minerals society source clays: Colloid and surface phenomena. Clays and Clay Minerals, 49, 446-452. 
672 Yariv, S. \& Lapides, I. (2003) Laser shadow analysis of particle-size distribution of 673 montmorillonites in aqueous suspensions. Clays and Clay Minerals, 51, 23-32.

674 Zbik, M. \& Smart, R.S.C. (1998) Nanomorphology of kaolinites: Comparative SEM and AFM 675 studies. Clays and Clay Minerals, 46, 153-160.

676 Zbik, M. \& Smart, R.S.C. (2002) Dispersion of kaolinite and talc in aqueous solution: Nano677 morphology and nano-bubble entrapment. Minerals Engineering, 15, 277-286.

678 Zbik, M.S. \& Frost, R.L. (2009) Micro-structure differences in kaolinite suspensions. Journal of 679 Colloid and Interface Science, 339, 110-116.

680 Zhang, G., Germaine, J.T. \& Whittle, A.J. (2005) An evaluation of the mechanical and chemical 681 dispersion methods for a tropical old alluvium. Geotechnical Testing Journal, 28, 123-132.

682 Zhang, G., Germaine, J.T., Whittle, A.J. \& Ladd, C.C. (2004) Index properties of a highly 683 weathered old alluvium. Geotechnique, 54, 441-451.

684 Zhang, Z.P., Liao, L.B. \& Xia, Z.G. (2010) Ultrasound-assisted preparation and characterization 685 of anionic surfactant modified montmorillonites. Applied Clay Science, 50, 576-581.

686

687

688 


\section{Table Captions}

690

691

692 Table 1. Origins and basic properties of the four clay minerals ${ }^{\mathrm{a}}$.

693 Table 2. Summary of all clay mineral dispersions prepared by different methods.

694 Table 3. Parameters of dry mode dispersion for the four clay minerals.

695 Table 4. Dielectric constant of different solvents at $25{ }^{\circ} \mathrm{C}$.

696 Table 5. Intrinsic PSD parameters of the four clay minerals.

697

698

699

700

701 
Table 1. Origins and basic properties of the four clay minerals ${ }^{\mathrm{a}}$.

\begin{tabular}{|c|c|c|c|c|c|c|c|}
\hline \multirow[t]{2}{*}{ Name } & \multirow[t]{2}{*}{ Origin } & \multirow{2}{*}{$\begin{array}{l}\mathrm{CEC}^{\mathrm{b}} \\
\text { (meq/ } \\
100 \mathrm{~g})\end{array}$} & \multicolumn{2}{|c|}{$\begin{array}{c}\text { Layer charge }{ }^{\mathrm{C}} \\
\text { (unbalanced charge) }\end{array}$} & \multirow{2}{*}{$\begin{array}{l}\mathrm{SSA}^{\mathrm{d}} \\
\left(\mathrm{m}^{2} / \mathrm{g}\right)\end{array}$} & \multirow[t]{2}{*}{$\mathrm{pH}^{\mathrm{e}}$} & \multirow[t]{2}{*}{ Chemical formula } \\
\hline & & & $\mathrm{T}$ & $\mathrm{O}$ & & & \\
\hline \multirow{2}{*}{$\begin{array}{l}\text { Kaolinite } \\
\text { (KGa-1b) }\end{array}$} & \multirow{2}{*}{$\begin{array}{c}\text { Washington } \\
\text { County, } \\
\text { Georgia } \\
\end{array}$} & \multirow{2}{*}{2.00} & \multicolumn{2}{|c|}{$-0.06(0)$} & \multirow{2}{*}{10.05} & \multirow{2}{*}{5.97} & \multirow{2}{*}{$\begin{array}{l}\left(\mathrm{Mg}_{.02} \mathrm{Ca}_{.01} \mathrm{Na}_{.01} \mathrm{~K}_{.01}\right) \\
{\left[\mathrm{Al}_{3.86} \mathrm{Fe}^{3+}{ }_{.02} \mathrm{Mn}_{\text {tr }} \mathrm{Ti}_{111}\right]} \\
{\left[\mathrm{Si}_{3.83} \mathrm{Al}_{.17}\right] \mathrm{O}_{10}(\mathrm{OH})_{8}}\end{array}$} \\
\hline & & & -0.17 & +0.11 & & & \\
\hline \multirow{2}{*}{$\begin{array}{l}\text { Illite } \\
\text { (IMt-1) }\end{array}$} & \multirow{2}{*}{$\begin{array}{l}\text { Silver Hill, } \\
\text { Montana }\end{array}$} & \multirow{2}{*}{$15.00^{\mathrm{f}}$} & \multicolumn{2}{|c|}{$-1.68(0)$} & \multirow{2}{*}{$\begin{array}{l}30.00^{\mathrm{g}} \\
\text { or } 24.9^{\mathrm{h}}\end{array}$} & \multirow{2}{*}{8.61} & \multirow{2}{*}{$\begin{array}{l}\left(\mathrm{Mg}_{.09} \mathrm{Ca}_{.06} \mathrm{~K}_{1.37}\right) \\
{\left[\mathrm{Al}_{2.69} \mathrm{Fe}^{3+}{ }_{.76} \mathrm{Fe}^{2+}{ }_{.06}\right.} \\
\left.\mathrm{Mn}_{\mathrm{tr}} \mathrm{Mg}_{.43} \mathrm{Ti}_{.06}\right] \\
{\left[\mathrm{Si}_{6.77} \mathrm{Al}_{1.23}\right] \mathrm{O}_{20}(\mathrm{OH})_{4}}\end{array}$} \\
\hline & & & -1.23 & -0.44 & & & \\
\hline \multirow{2}{*}{$\begin{array}{l}\mathrm{Ca}^{2+}-\mathrm{Mt} \\
(\mathrm{STx}-1 \mathrm{~b})\end{array}$} & \multirow{2}{*}{$\begin{array}{l}\text { Gonzales } \\
\text { County, } \\
\text { Texas }\end{array}$} & \multirow{2}{*}{84.40} & \multicolumn{2}{|c|}{$-0.68(-0.08)$} & \multirow{2}{*}{83.79} & \multirow{2}{*}{7.32} & \multirow{2}{*}{$\begin{array}{l}\left(\mathrm{Ca}_{.27} \mathrm{Na}_{.04} \mathrm{~K}_{.01}\right) \\
{\left[\mathrm{Al}_{2.41} \mathrm{Fe}^{3+}{ }_{.09} \mathrm{Mn}_{\text {tr }}\right.} \\
\left.\mathrm{Mg}_{.71} \mathrm{Ti}_{.03}\right]\left[\mathrm{Si}_{8.00}\right] \\
\mathrm{O}_{20}(\mathrm{OH})_{4}\end{array}$} \\
\hline & & & 0 & -0.68 & & & \\
\hline \multirow{2}{*}{$\begin{array}{l}\mathrm{Na}^{+}-\mathrm{Mt} \\
(\mathrm{SWy}-2)\end{array}$} & \multirow{2}{*}{$\begin{array}{l}\text { Crook } \\
\text { County, } \\
\text { Wyoming }\end{array}$} & \multirow[t]{2}{*}{76.40} & \multicolumn{2}{|c|}{$-0.55(+0.05)$} & \multirow[t]{2}{*}{31.82} & \multirow[t]{2}{*}{6.44} & \multirow{2}{*}{$\begin{array}{l}\left(\mathrm{Ca}_{.12} \mathrm{Na}_{32} \mathrm{~K}_{.05}\right) \\
{\left[\mathrm{Al}_{3.01} \mathrm{Fe}^{+3}{ }_{.41} \mathrm{Mn}_{.01}\right.} \\
\mathrm{Mg}_{.51} \mathrm{Ti}_{.02} \\
{\left[\mathrm{Si}_{7.98} \mathrm{Al}_{.02}\right] \mathrm{O}_{20}(\mathrm{OH})_{4}}\end{array}$} \\
\hline & & & -0.53 & -0.02 & & & \\
\hline
\end{tabular}

${ }^{a}$ All data except those noted are taken from the Clay Minerals Society Source Clay Data Sheets.

${ }^{\mathrm{b}} \mathrm{CEC}=$ cation exchange capacity.

${ }^{c}$ The layer charge is based on per $\mathrm{O}_{10}(\mathrm{OH})_{8}$ for kaolinite and $\mathrm{O}_{20}(\mathrm{OH})_{4}$ for the other three clay minerals; O: charge from octahedral sheet; T: charge from tetrahedral sheets.

${ }^{\mathrm{d}} \mathrm{SSA}=$ specific surface area.

${ }^{\mathrm{e}} \mathrm{pH}$ of the suspension at a concentration of $0.4 \mathrm{~g} / \mathrm{L}$ in deionized water at room temperature (23 ${ }^{\circ} \mathrm{C}$ ) obtained by a $\mathrm{pH}$ meter (Thermo Scientific Orion $\mathrm{Star}^{\mathrm{TM}}$ Series).

${ }^{\mathrm{f}}$ Data from Hower and Mowatt (1966), and Kinter and Diamond (1958).

${ }^{\mathrm{g}}$ Data from Celis and Koskinen (1999).

${ }^{\mathrm{h}}$ Data from (Goldberg et al., 1996). 
Table 2. Summary of all clay mineral dispersions prepared by different methods.

\begin{tabular}{|c|c|c|c|c|}
\hline \multicolumn{2}{|c|}{ Method } & Sample preparation & Samples & Purpose \\
\hline \multirow{5}{*}{$\begin{array}{c}\text { I } \\
\text { (Liquid } \\
\text { mode) }\end{array}$} & A & $\begin{array}{l}\text { Probe-type ultrasound for } 15 \text { mins, } \\
\text { followed by } 3.5 \mathrm{hrs} \text { settling }\end{array}$ & $\begin{array}{l}\text { All } 4 \text { clay } \\
\text { minerals }\end{array}$ & $\begin{array}{l}\text { Obtain the }<2 \mu \mathrm{m} \\
\quad \text { fractions }\end{array}$ \\
\hline & $\mathrm{B}$ & $\begin{array}{l}\text { Unsoaking vs. overnight soaking in } \\
\text { water }\end{array}$ & $\begin{array}{l}\text { All } 4 \text { clay } \\
\text { minerals }\end{array}$ & $\begin{array}{c}\text { Investigate the influence } \\
\text { of overnight soaking }\end{array}$ \\
\hline & $\mathrm{C}$ & Probe-type ultrasound for 15 mins & $\begin{array}{l}\text { All } 4 \text { clay } \\
\text { minerals }\end{array}$ & $\begin{array}{l}\text { Evaluate mechanical } \\
\text { disaggregation }\end{array}$ \\
\hline & $\mathrm{D}$ & $\begin{array}{l}\text { Disperse in a } 40 \mathrm{~g} / \mathrm{L} \text { sodium } \\
\text { hexametaphosphate solution }\end{array}$ & $\begin{array}{l}\text { All } 4 \text { clay } \\
\text { minerals }\end{array}$ & $\begin{array}{c}\text { Evaluate a chemical } \\
\text { dispersant }\end{array}$ \\
\hline & $\mathrm{E}$ & $\begin{array}{l}3 \text { solvents: EA, } 2 \text { vol.\% glycerol in } \\
\text { EA, and } 2 \text { vol.\% glycerol in DI } \\
\text { water }\end{array}$ & $\begin{array}{l}\text { Only } \mathrm{Ca}^{2+}-\mathrm{Mt} \\
\text { and } \mathrm{Na}^{2+}-\mathrm{Mt}\end{array}$ & $\begin{array}{l}\text { Investigate the influence } \\
\text { of swelling }\end{array}$ \\
\hline \multicolumn{2}{|c|}{$\begin{array}{c}\text { II } \\
\text { (Dry mode) }\end{array}$} & $\begin{array}{l}\text { Dispersed in and transported by } \\
\text { pressurized dry air }\end{array}$ & $\begin{array}{l}\text { All } 4 \text { clay } \\
\text { minerals }\end{array}$ & Evaluate dry dispersion \\
\hline
\end{tabular}


Table 3. Parameters of dry mode dispersion for the four clay minerals.

\begin{tabular}{|c|c|c|c|c|c|}
\hline Sample & $\begin{array}{c}\text { Mass of sample per } \\
\text { measurement }(\mathrm{g})\end{array}$ & $\begin{array}{c}\text { Obscuration } \\
\text { rate }\end{array}$ & $\begin{array}{c}\text { Vibration } \\
\text { frequency } \\
(\mathrm{Hz})\end{array}$ & $\begin{array}{c}\text { Cyclic ratio } \\
\text { of vibration }\end{array}$ & $\begin{array}{c}\text { Air pressure } \\
\text { (mbar) }\end{array}$ \\
\hline Kaolinite & 1.8 & $18 \%$ & 50 & $40 \%$ & 400 \\
\hline Illite & 1.0 & $14 \%$ & 50 & $35 \%$ & 350 \\
\hline $\mathrm{Ca}^{2+}-\mathrm{Mt}$ & 2.0 & $16 \%$ & 50 & $40 \%$ & 500 \\
\hline $\mathrm{Na}^{2+}-\mathrm{Mt}$ & 3.0 & $14 \%$ & 50 & $40 \%$ & 400 \\
\hline
\end{tabular}


Table 4. Dielectric constant of different solvents at $25^{\circ} \mathrm{C}$.

\begin{tabular}{|c|c|}
\hline Solution or solvent & Dielectric constant \\
\hline Deionized water & 80.3 \\
\hline Ethyl alcohol & 24.3 \\
\hline Glycerol & 42.5 \\
\hline 2 vol.\% glycerol in deionized water & $79.5^{*}$ \\
\hline 2 vol.\% glycerol in ethyl alcohol & $24.7^{*}$ \\
\hline
\end{tabular}

* Dielectric constant estimated based on a relationship proposed by (Jouyban et al., 2004). 
Table 5. Intrinsic PSD parameters of the four clay minerals.

\begin{tabular}{|c|c|c|c|c|c|c|}
\hline Sample & Dispersion method & $\begin{array}{c}D_{10} \\
(\mu \mathrm{m})\end{array}$ & $\begin{array}{c}D_{50} \\
(\mu \mathrm{m})\end{array}$ & $\begin{array}{c}D_{90} \\
(\mu \mathrm{m})\end{array}$ & $\begin{array}{c}C_{\mathrm{u}}= \\
D_{60} / D_{10}\end{array}$ & $\begin{array}{c}C_{\mathrm{c}}= \\
\left(D_{30}\right)^{2} /\left(D_{10} * D_{60}\right)\end{array}$ \\
\hline Kaolinite & Dispersed in NaHMP solution & 0.63 & 3.56 & 19.41 & 14.44 & 0.39 \\
\hline Illite & $\begin{array}{c}\text { Overnight soaking / Dispersed } \\
\text { in NaHMP solution }\end{array}$ & 0.76 & 6.37 & 15.94 & 11.32 & 0.81 \\
\hline $\mathrm{Ca}^{2+}-\mathrm{Mt}$ & Dispersed in alcohol & 1.87 & 12.98 & 32.75 & 8.56 & 2.14 \\
\hline $\mathrm{Na}^{+}-\mathrm{Mt}$ & Dispersed in alcohol & 1.56 & 12.26 & 31.91 & 9.94 & 2.03 \\
\hline
\end{tabular}

$C_{\mathrm{u}}$ is the coefficient of uniformity, defined as the ratio of $D_{60}$ to $D_{10} ; C_{\mathrm{c}}$ is the coefficient of curvature, defined as the ratio of squared $D_{30}$ to the product of $D_{10}$ and $D_{60}$. 


\section{Figure Captions}

703

704

705

706

707

708

709

710

711

712

713

714

715

716

717

718
Figure 1. X-ray diffraction pattern of the processed illite powdery sample.

Figure 2. Schematic diagram showing the dry mode system (left) and liquid dispersion and circulation system with an inverted microscope for particle imaging (right) of the Cilas PSA.

Figure 3. PSD curves of the $<2 \mu \mathrm{m}$ fraction of the four clay minerals. Note: P refers to the cumulate percentage, while F refers the occurrence frequency of each size. Same for other figures.

Figure 4. Schematic diagram showing the swelling of mixed $\mathrm{Ca}^{2+} / \mathrm{Na}^{+}$-montmorillonite in water.

Figure 5. Effect of overnight soaking in water on the PSD of the four clay minerals.

Figure 6. Optical microscope images of clay minerals: (a) kaolinite in DI water, (b) illite in DI water, (c) $\mathrm{Ca}^{2+}$-Mt in DI water, (d) $\mathrm{Na}^{+}-\mathrm{Mt}$ in DI water, (e) $\mathrm{Ca}^{2+}$-Mt in EA, and (f) $\mathrm{Na}^{+}-\mathrm{Mt}$ in EA (Scale bar: $50 \mu \mathrm{m}$ ).

Figure 7. PSD curves of the four clay minerals obtained by different dispersion methods.

Figure 8. PSD curves of two montmorillonites in different dispersion solvents. 


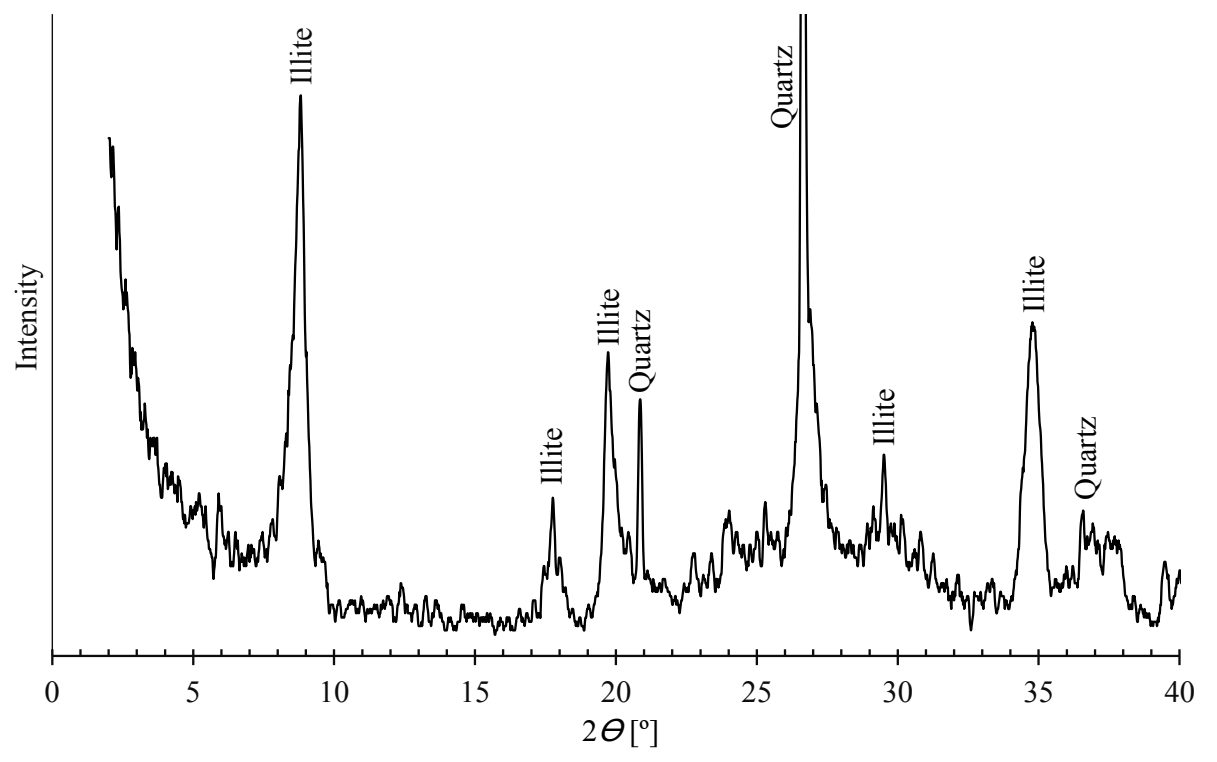

Figure 1. X-ray diffraction pattern of the processed illite powdery sample. 


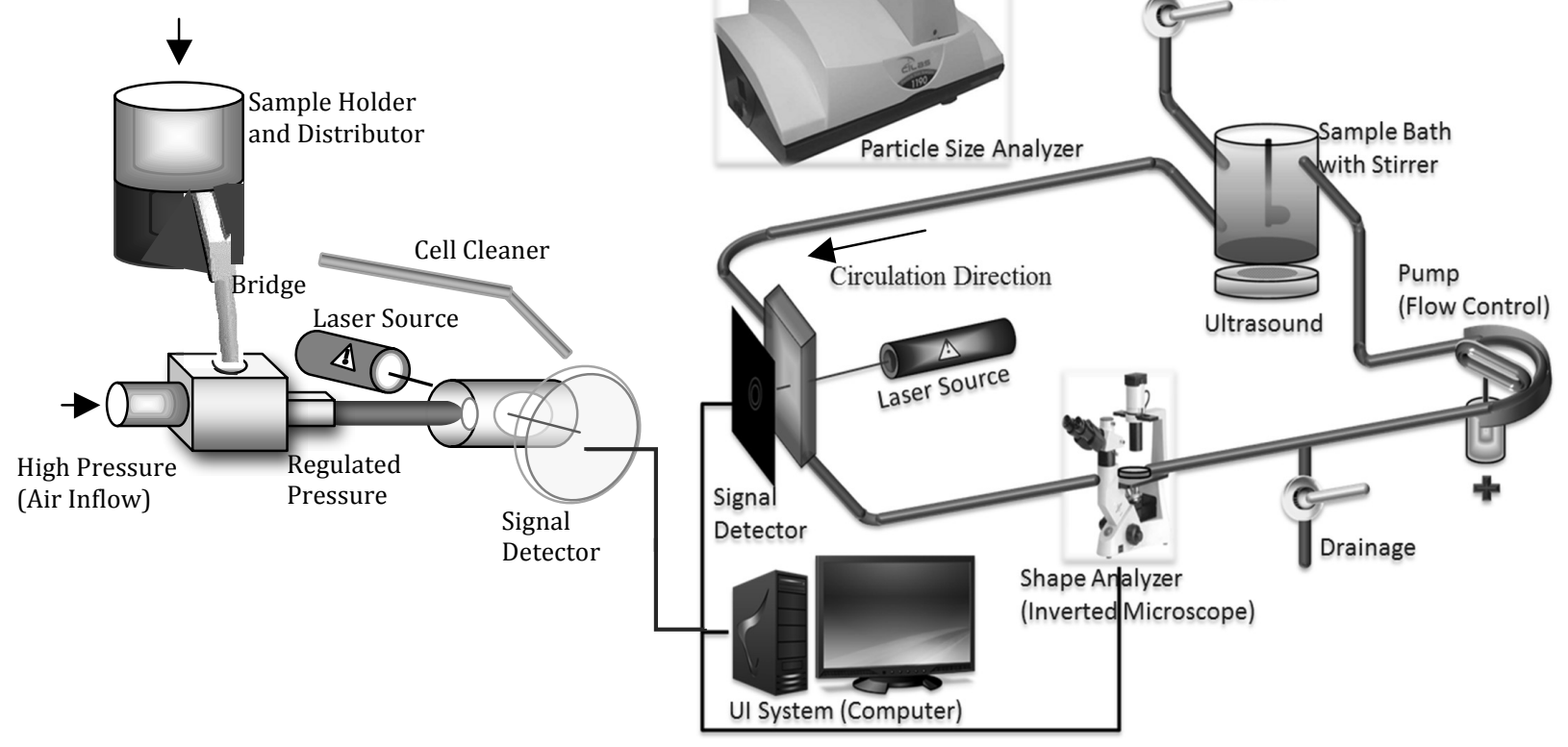

Figure 2. Schematic diagram showing the dry mode system (left) and liquid dispersion and circulation system with an inverted microscope for particle imaging (right) of the Cilas PSA. 

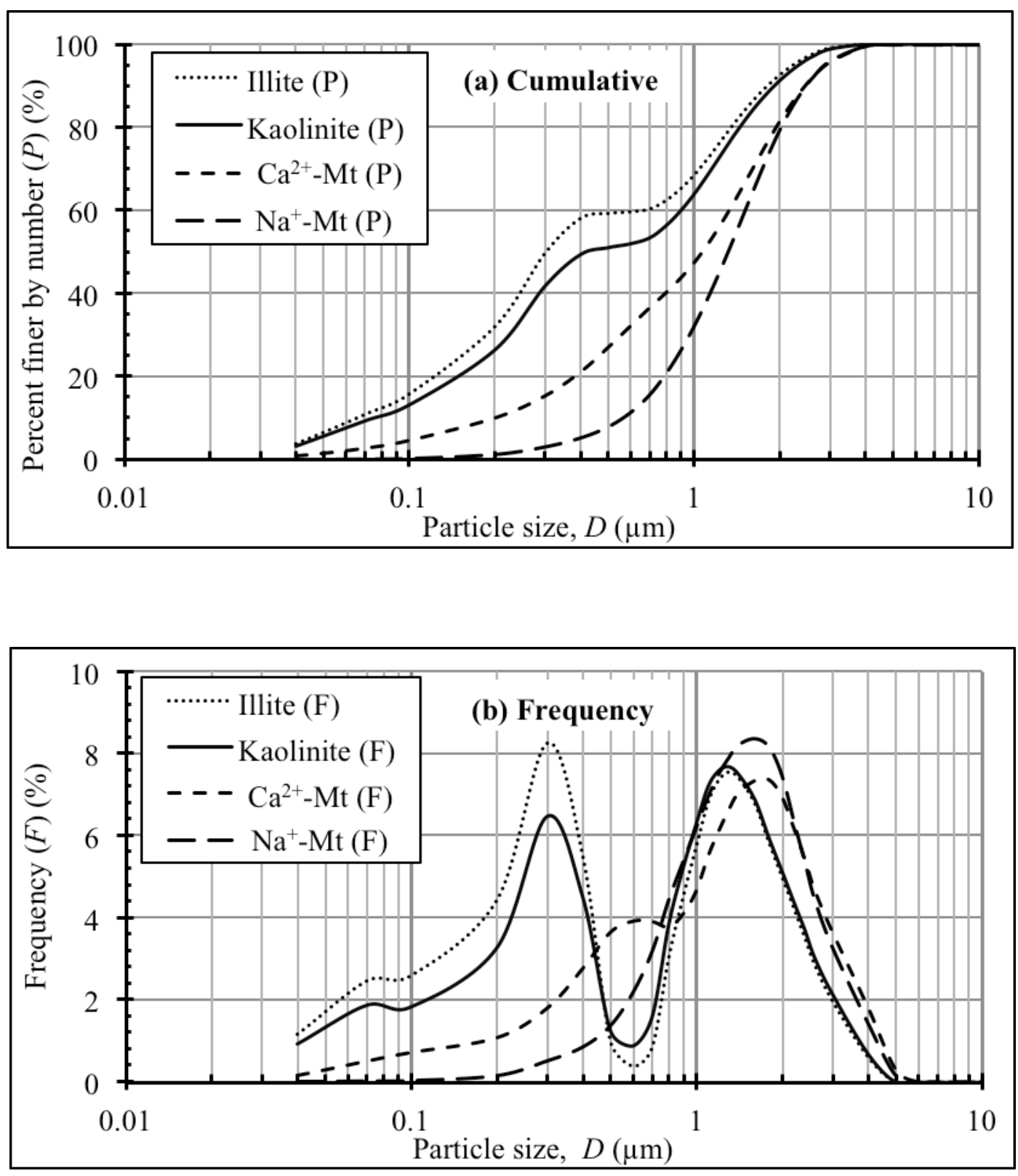

Figure 3. PSD curves of the $<2 \mu \mathrm{m}$ fraction of the four clay minerals. Note: P refers to the cumulate percentage, while F refers the occurrence frequency of each size. Same for other figures. 


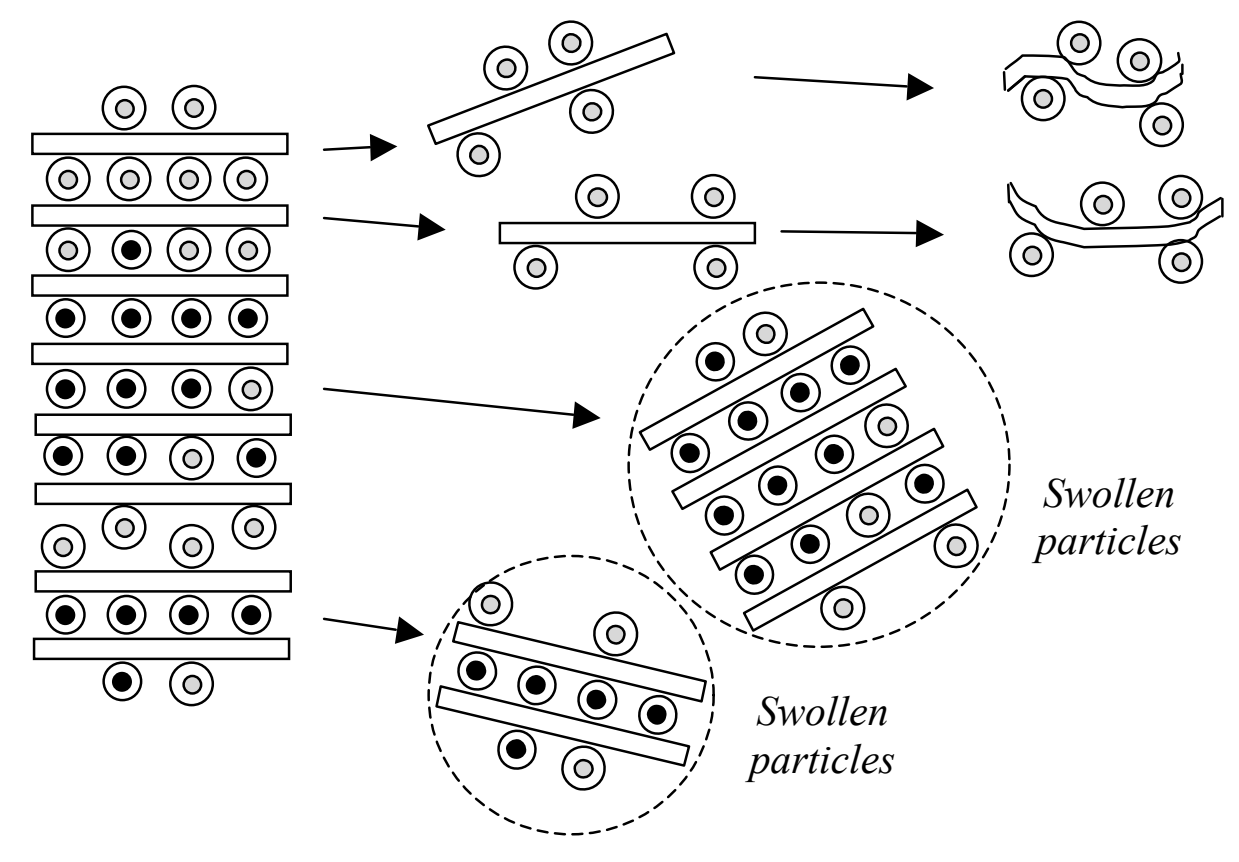

2:1 clay layer $\bigcirc$ Hydrated $\mathrm{Ca}^{2+}$ (O) Hydrated $\mathrm{Na}^{+}$

Figure 4. Schematic diagram showing the swelling of mixed $\mathrm{Ca}^{2+} / \mathrm{Na}^{+}$-montmorillonite in water. 

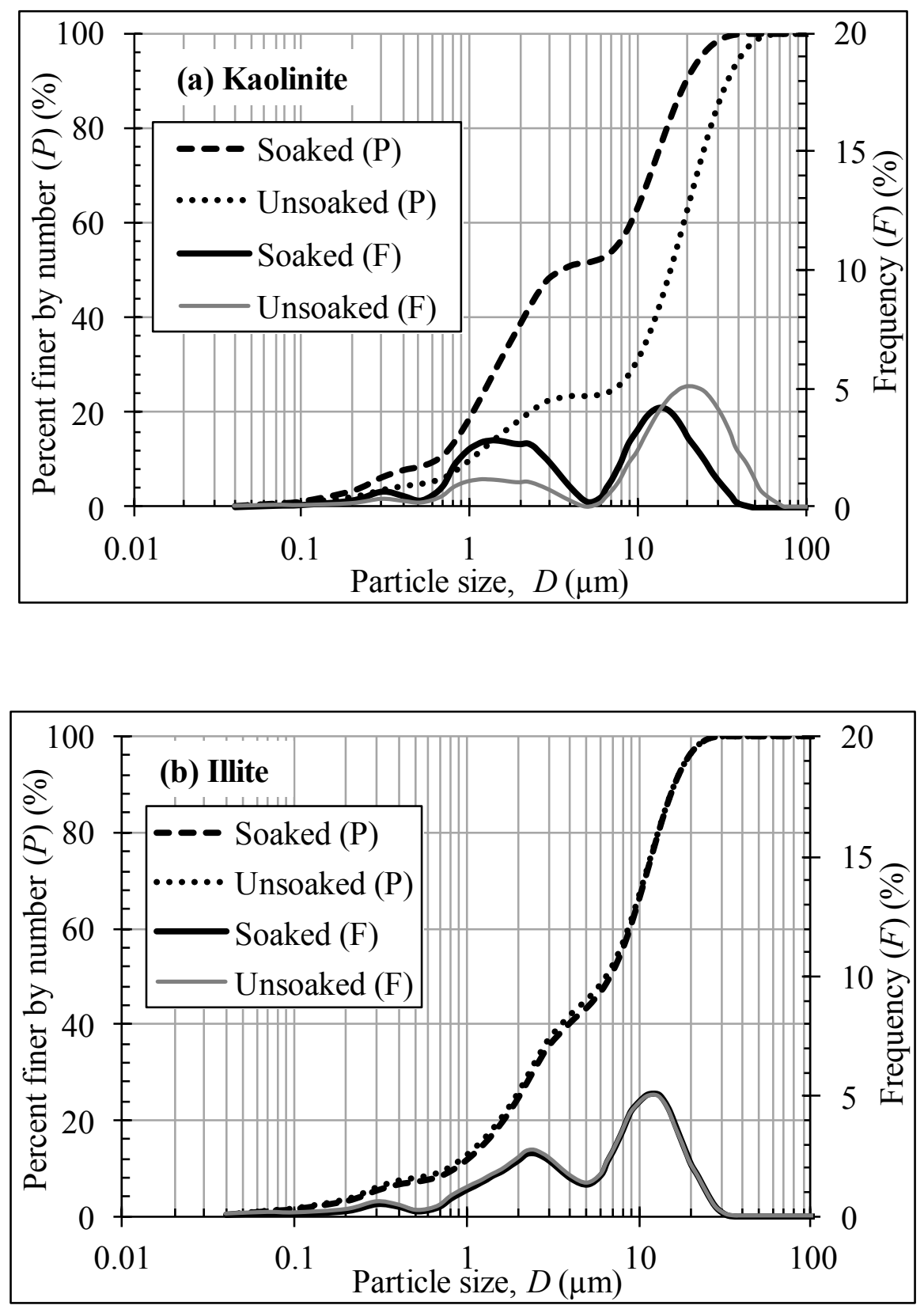

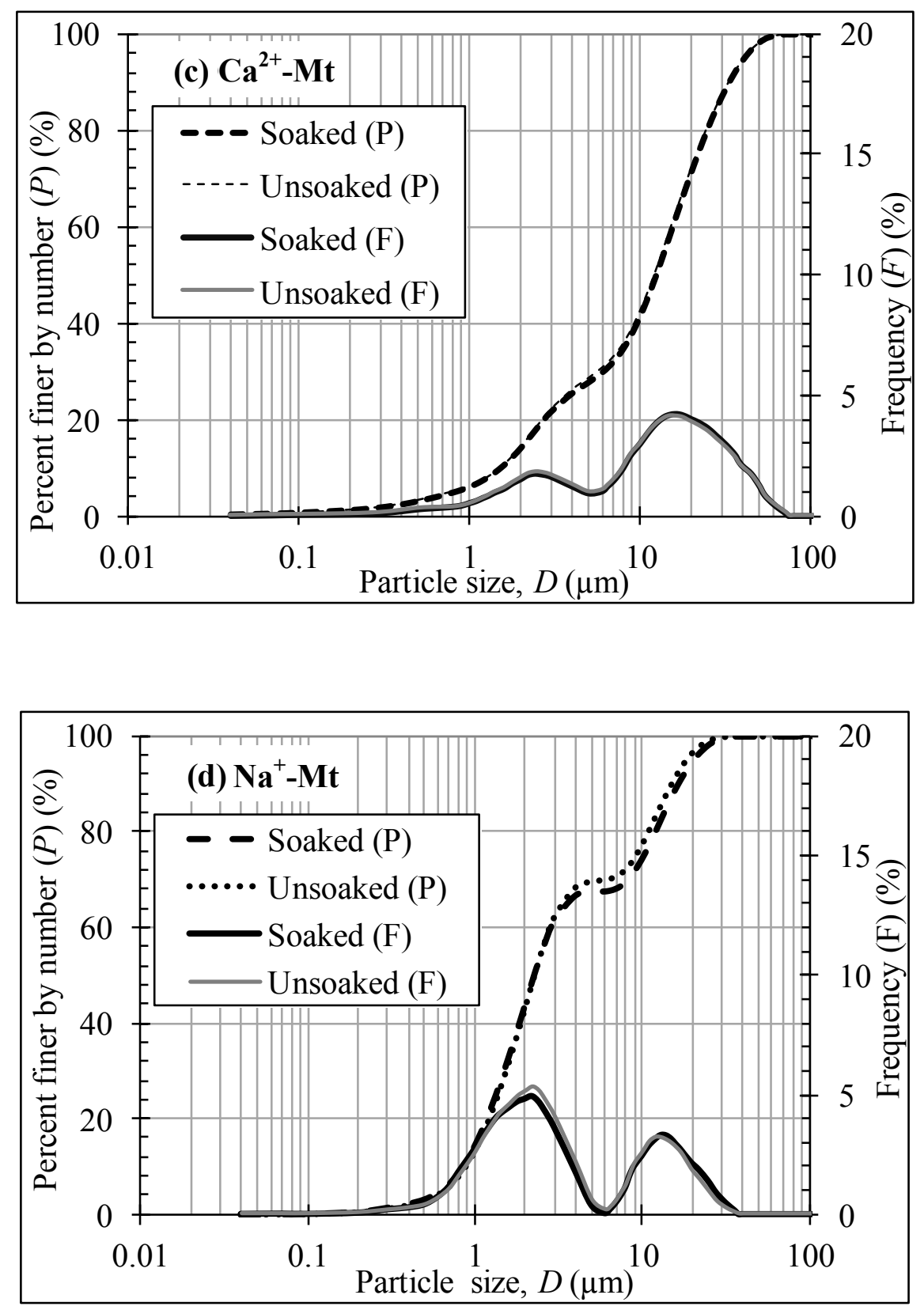

Figure 5. Effect of overnight soaking in water on the PSD of the four clay minerals. 

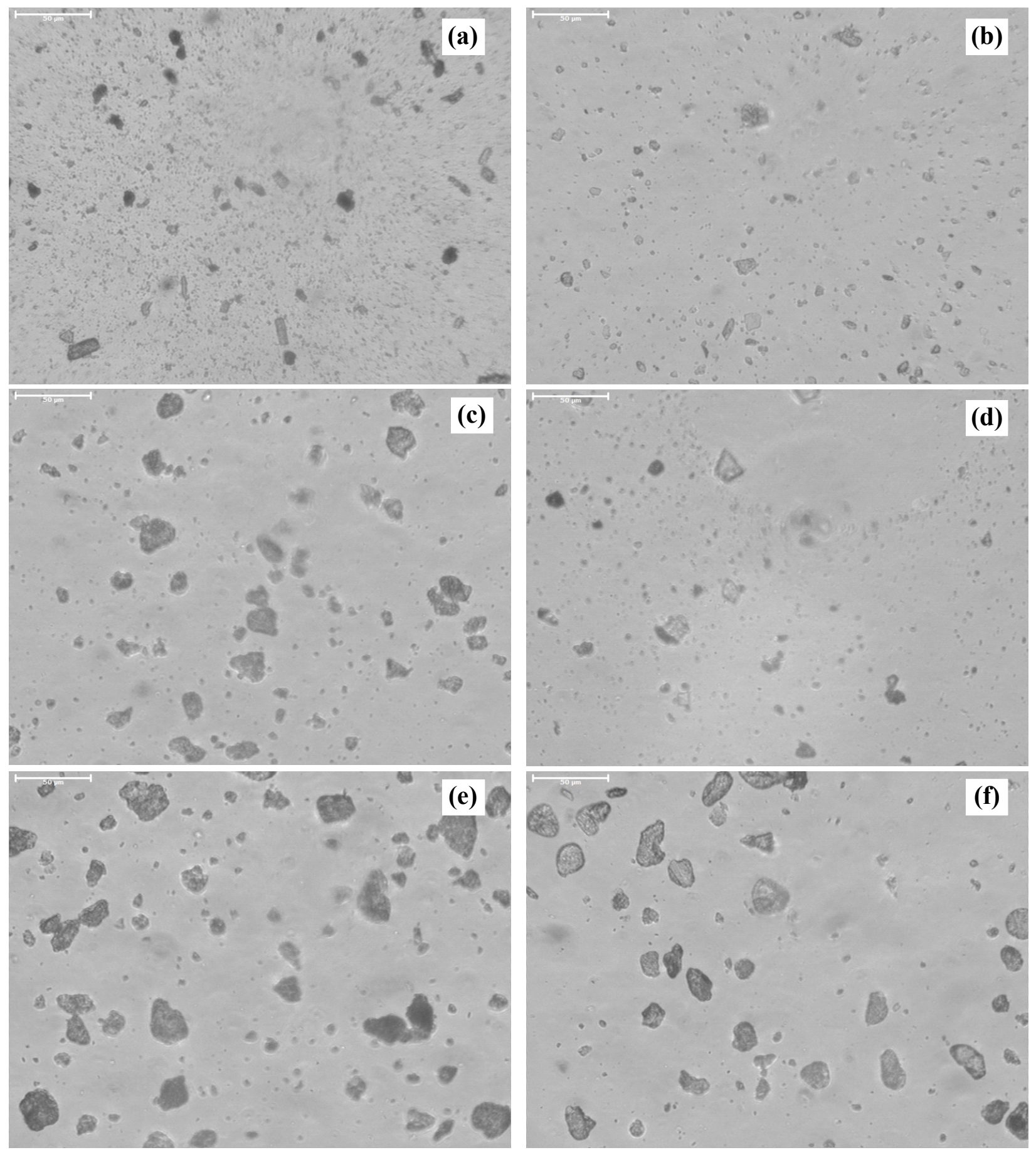

Figure 6. Optical microscope images of clay minerals: (a) kaolinite in DI water, (b) illite in DI water, (c) $\mathrm{Ca}^{2+}$-Mt in DI water, (d) $\mathrm{Na}^{+}-\mathrm{Mt}$ in DI water, (e) $\mathrm{Ca}^{2+}-\mathrm{Mt}$ in EA, and (f) $\mathrm{Na}^{+}-\mathrm{Mt}$ in EA (Scale bar: $50 \mu \mathrm{m}$ ). 

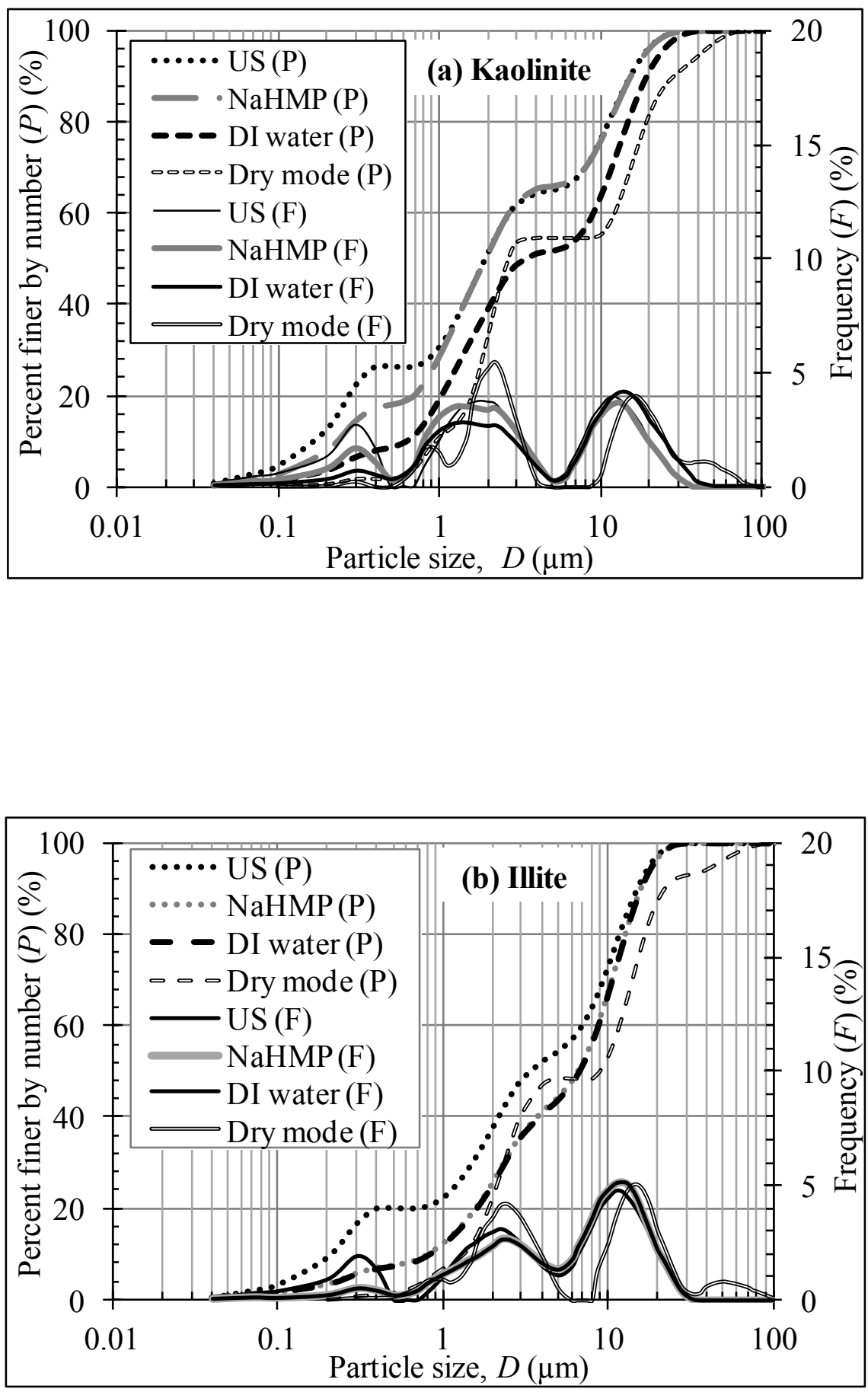

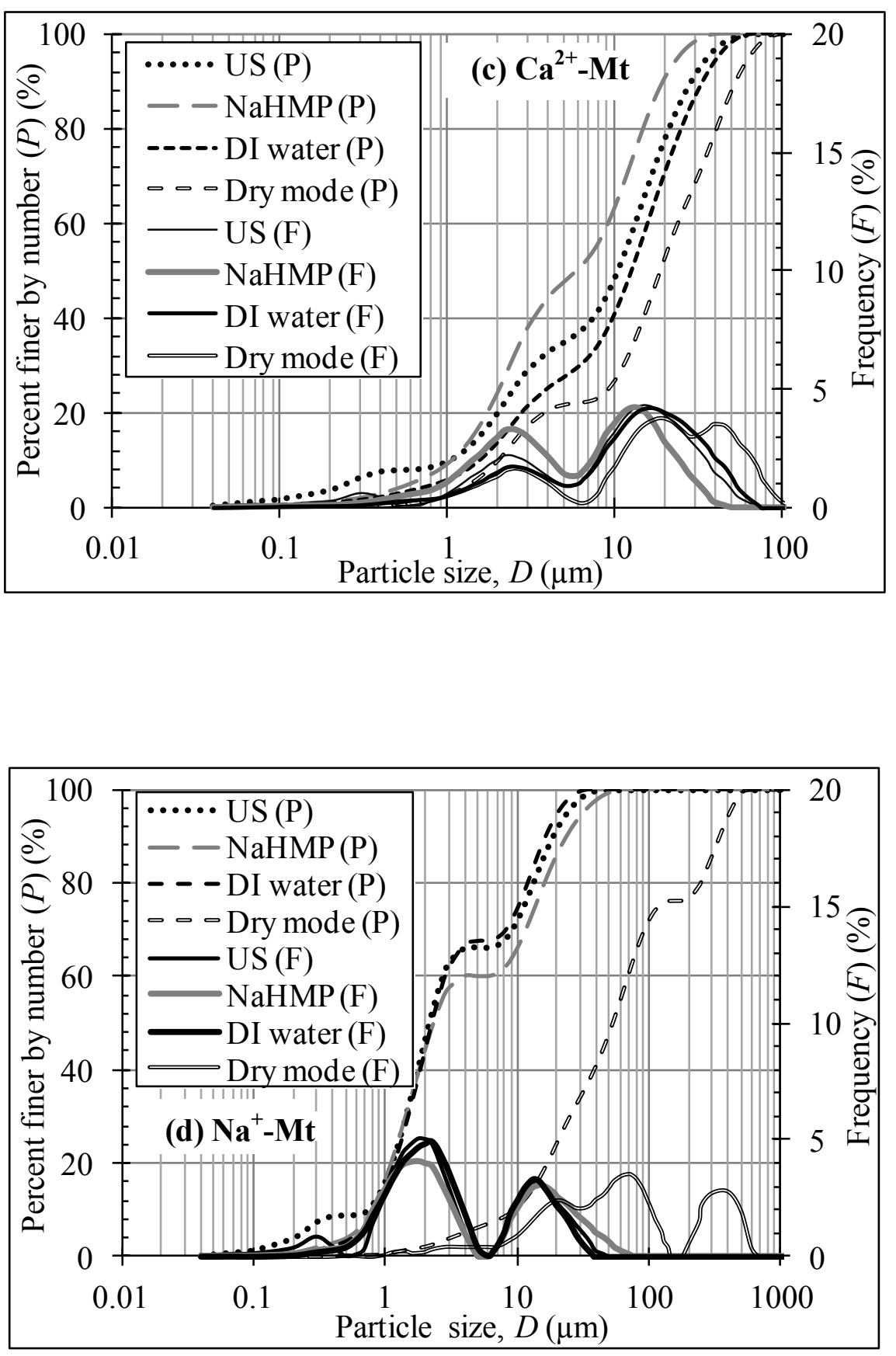

Figure 7. PSD curves of the four clay minerals obtained by different dispersion methods. 

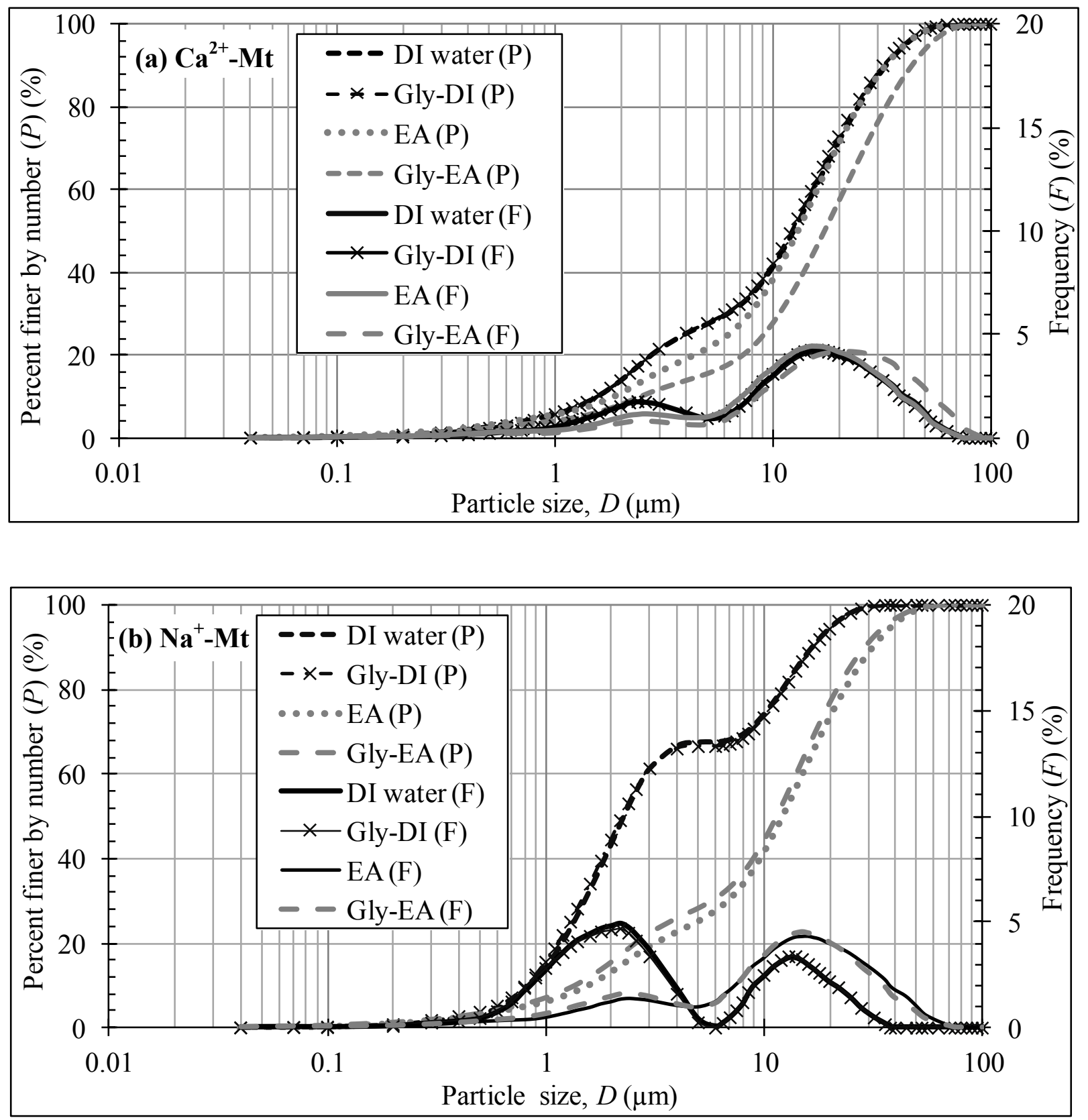

Figure 8. PSD curves of two montmorillonites in different dispersion solvents. 
Evaluation of the particle sizes of four clay minerals

\author{
Graphical Abstract
}

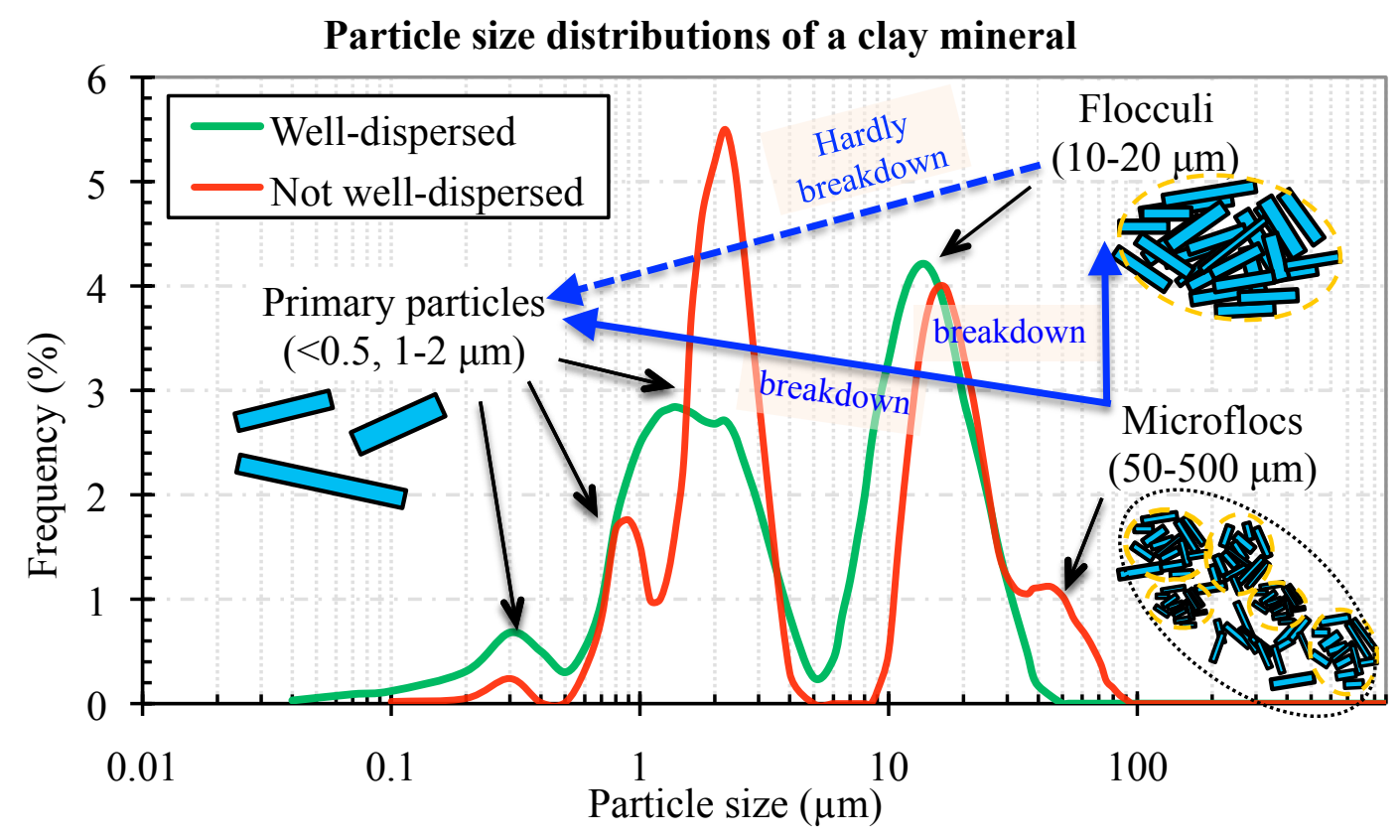

